\title{
Surprise, Surprise - Measuring Firm-level Investment Innovations
}

\author{
Rüdiger Bachmann Steffen Elstner Atanas Hristov*
}

February 13, 2014

\begin{abstract}
Firms expect certain investment expenditures. Firms realize certain investment expenditures. The difference is an investment surprise. With the help of the IFO Investment Survey for the German manufacturing sector we measure firms' (quantitative) investment expectations and firms' (quantitative) investment realizations on a yearly basis and construct a panel of firm-level investment innovations. This paper documents its cross-sectional and time-series properties and thus provides direct, econometrics-free quantitative discipline on the idiosyncratic shock processes used in structural heterogeneous-firm models. We find: 1) there is excess kurtosis in investment innovations, but no significant skewness; 2) the cross-sectional average of investment innovations is procyclical; 3) the cross-sectional dispersion of investment innovations is countercyclical; 4) the cross-sectional skewness and kurtosis of investment innovations is largely acyclical; 5) the cross-sectional average of the firm-individual time series volatility of investment innovations is countercyclical and highly positively correlated with the cross-sectional dispersion of investment innovations; 6) measures of firm-idiosyncratic risk have sizeable fluctuations, in the range of aggregate investment fluctuations.
\end{abstract}

JEL Codes: E20, E22, E30, E32.

Keywords: survey data, expectation errors, firm data, investment, idiosyncratic shocks, higher moments.

\footnotetext{
*Respectively: RWTH Aachen University, CEPR, CESifo and IFO Institute, Email: ruediger.bachmann@rwth-aachen.de; Staff of the German Council of Economic Experts (Sachverständigenrat), Email: steffen.elstner@destatis.de; IFO Institute, Email: hristov.a@ifo.de. We are grateful to Annette Weichselberger from the IFO Institute for helping us with the data and introducing us to the institutional backgrounds.
} 


\section{Introduction}

This is a measurement paper. We study the empirical properties of quantitative investment innovations (or surprises, which we will use interchangeably) in (West-)German manufacturing firms. An investment innovation/surprise is defined as an investment expectation error, i.e., the difference between an investment expectation for a given year and the investment realization for that same year.

To understand the behavior of firms, researchers need to understand the nature of the shocks that firms face. To calibrate heterogeneous-firm models, researchers need to know the stochastic properties of these shocks. However, in order to measure truly exogenous shocks, economists would require knowledge of both the expectations of firms regarding their exogenously given business environment and also the actual realizations of the determinants of said business environment. Such data, especially about firms' expectations, do not exist and would be difficult to obtain. What economists have often done instead is to use econometric models to extract firms' expectations or reverse-engineer stochastic processes to match certain firm-level outcome variables, e.g., the distribution of firm-level sales growth rates or of firm-level investment rates.

The novelty of our approach is to use confidential survey data on investment expectations of firms and data on how much firms in a given year actually invested, i.e., we know both investment expectations and quantitative investment realizations of a given firm in a given year in a quantitative form. This allows us to compute true investment surprises at the firm level, and, given that we observe these investment surprises over a fairly long time period and for a large number of firms, to construct an (unbalanced) panel of these investment surprises. From this we then establish long-run, cross-sectional and cross-sectional cum time-series properties of investment surprises.

Given the nature of these data - surprises as opposed to mere outcome variables - we can contribute, somewhat conclusively, to the settling of a few open questions about the nature of firm-level shocks. For example, do data on the dispersion of various firm-level variables identify firm-level volatility processes well? Our answer is yes. Or: is time-varying firm-level risk a matter of time-varying second moments or should researchers worry about higher moments, too? Our answer is no.

To be clear: our data only gives us first-moment investment expectations, firms' expected investment, not firms' subjective uncertainty around these expectations or even the entire probability distribution of expectations. Such data do not seem to exist, at least over a relatively long time horizon. ${ }^{1}$ Also, from a model-theoretic perspective, we do not measure

\footnotetext{
${ }^{1}$ The one imperfect exception to this we know of is the Italian Survey on Investment in Manufacturing,
} 
surprises in quantities that are usually considered as exogenous to the firm, like idiosyncratic TFP levels or idiosyncratic demand. Our surprise measure is for an endogenous variable, firm-level investment. However, again, to the best of our knowledge firm-level data sets that elicit expectation distributions and/or expectations for concepts such as TFP or demand, let alone over a long time horizon, do not exist. Thus, we view our approach as the next best possible. In any event, through the lens of a given structural heterogeneous-firm model, the stochastic properties of our investment innovation measures will identify the stochastic properties of the underlying exogenous shocks. Researchers interested in such models can then use our data and their quantitative stochastic properties to calibrate the shock processes they feed into their models. What is novel in our approach is that we use data directly on expectations without having to resort to econometric models and can thus compute investment surprises, as opposed to mere investment levels or changes.

Our primary data source is the IFO Investment Survey (IFO-IS). This survey is particularly well suited for our research question as it provides quantitative information on expected and realized investment for various expectation horizons and does so over a rather long time period. $^{2}$ The IFO-IS is a semiannual survey that covers all industries of West German manufacturing plus the mining industry. It asks firms in the spring and fall of each year about their investment plans for the upcoming year and their actual investments undertaken in the current and the preceding year. The data goes back to 1970, so we can compute a panel of investment surprises for roughly forty years. Another advantage of these survey micro data is that they are highly confidential, which means that investment expectations are less likely to be subject to strategic behavior of the sort that we might be concerned about in, e.g., public earnings announcements that firms might use for signalling to the market.

used by Bontempi, Golinelli, and Parigi (2010) and Guiso and Parigi (1999), which asks firms not only about their expected sales growth, but also about their max-min sales growth range. However, the time series of this survey is too short to derive business cycle properties of firm-level sales surprises. Of course, the situation on the household side, owing to the pioneering work of Charles Manski (see, for instance, Bellemare and Manski (2011)) is different in this regard.

${ }^{2}$ This distinguishes the IFO-IS from other business surveys that very often only have qualitative, up-downunchanged expectation and realization data. Notable exceptions are the Canadian Capital Expenditures Survey for the manufacturing sector (see Dave (2011)), the aforementioned Italian example or the annual German IAB Establishment Panel (see Müller (2011)) with, however, a much shorter time in existence. Another, now defunct example in the U.S. is the BEA survey of business expenditures on plant and equipment (see de Leeuw and McKelvey $(1981,1984)$ ) with quantitative annual expectation data about aggregate prices. The IFO institute itself has another survey with qualitative expectations about many more firm-level variables, which has been used in the literature (see Bachmann, Elstner, and Sims (2013), Bachmann and Elstner (2013) and Bachmann, Born, Elstner, and Grimme (2013)). In the U.S., there are the Philadelphia FED Business Outlook Survey and the Small Business Economic Trends Survey by the National Foundation of Independent Businesses (see Bachmann, Elstner, and Sims (2013)) with a plethora of qualitative firmlevel expectations. However, to derive quantitative expectation errors from these surveys quantification assumptions are needed, see Bachmann and Elstner (2013) or Müller and Köberl (2007), the latter for Swiss data. 
What are the stochastic properties of the investment innovations derived from the IFOIS? We have the following results: First, the pooled distribution of all investment surprises, which measures the long-run properties of investment surprises, displays excess kurtosis in investment innovations for all expectation horizons, but no significant skewness. The excess kurtosis shrinks somewhat with the horizon of the investment expectations. Second, the cross-sectional average of investment innovations is procyclical. Third, the cross-sectional dispersion of investment innovations is countercyclical. Fourth, the cross-sectional skewness and kurtosis of investment innovations is largely acyclical, if anything, mildly procyclical. Fifth, the cross-sectional average of the firm-individual time series volatility of investment innovations is countercyclical and highly positively correlated with the cross-sectional dispersion of investment innovations. Sixth, the volatility of both the cross-sectional dispersion and the average of the firm-individual time series volatility of investment innovations is sizeable, in the range of the volatility of aggregate investment fluctuations. Seventh, and finally, the level of firm-level investment, normalized by various measures of firm size, is procyclically disperse.

The first finding about the excess kurtosis and the absence of skewness in the long-run distribution of investment innovations means that the structural shocks that firms are exposed to are likely being drawn from a symmetric distribution with fat tales. ${ }^{3}$ The second finding is to be expected, but the third finding about the countercyclicality of investment innovation dispersions belongs to a growing literature on the cyclicality of the dispersion of firm-level variables, although none of them, given the aforementioned data limitations, are true surprises, but rather growth rates or even simple levels. Researchers have documented that, across different countries and data sets, the dispersion of changes in firm- (or plant-) level variables, such as output, productivity, prices and business forecasts, is robustly countercyclical. Bachmann and Bayer (2013a), Bachmann and Bayer (2013b), Bloom, Floetotto, Jaimovich, Saporta-Eksten, and Terry (2012), Döpke, Funke, Holly, and Weber (2005), Döpke and Weber (2006), Gourio (2008), Higson, Holly, and Kattuman (2002), Higson, Holly, Kattuman, and Platis (2004) do so for output and/or productivity growth, Kehrig (2012) for productivity levels, Berger and Vavra (2011) for price changes, and Bachmann, Elstner, and Sims (2013) for business forecasts. ${ }^{4}$

\footnotetext{
${ }^{3}$ Bachmann and Bayer (2013b) and Midrigan (2011) have indirectly inferred this property of firm-level shocks from data on, respectively, firm-level Solow residual growth rates and price changes.

${ }^{4}$ The notable exception is documented in Bachmann and Bayer (2013a) - for German, U.S. and UK firm-level data - and Kehrig and Vincent (2013) - for U.S. manufacturing plant-level data -, which show that the dispersion of investment rates is robustly and statistically significantly, if mildly, procyclical. We confirm this finding here too (our seventh result), although we use firm-level investment normalized by firmlevel sales or employment instead of the firm-level capital stocks. Thus, this paper is the first to find in the same data set, for the same set of firms, the coexistence of countercyclically disperse investment innovations
} 
Our fourth result means that there is little evidence of systematic behavior of the firmlevel shock distribution over the business cycle beyond the second moment. Baker and Bloom (2013) have recently suggested to conceptualize the shock process that economic agents are exposed to as a stochastic process where not only the first moment is fluctuating over time, but where the entire distribution that economic agents draw from can be time-varying. With aggregate stock market data, Baker and Bloom (2013) also find little evidence that higherthan-the-second moments matter for aggregate shocks. ${ }^{5}$

Finally, this paper is to the best of our knowledge the first to compare systematically the business cycle behavior of the cross-sectional dispersion of investment innovations with the business cycle behavior of the cross-sectional average and the standard deviation of the individual-by-firm time series volatility of these investment innovations (see for long-run studies of these two concepts of firm-level volatility Comin and Mulani (2006) and Davis, Haltiwanger, Jarmin, and Miranda (2006)). This concerns our fifth and sixth result. We find that both the cross-sectional average and the standard deviation of the individual-by-firm time series volatility of the investment innovations are highly countercyclical and each is positively correlated with the cross-sectional dispersion of investment innovations. We also provide some evidence that the fluctuations of the cross-sectional dispersion are mainly driven by the individual-by-firm time series volatility of these investment innovations. This means that, to the extent that fluctuations in realized firm-specific volatility are the result of riskshocks, as much of the literature has interpreted them, ${ }^{6}$ we provide the most direct evidence for the existence of sizeable and countercyclical firm-idiosyncratic risk shocks yet. At the same time, we also provide support for the widespread practice of using time-varying crosssectional dispersion measures as evidence, proxies and calibration devices for time-varying idiosyncratic risk shocks, especially in those cases where only cross-sectional dispersion data are available, i.e., the panel dimension in the data is absent.

Why are these results important? Recently, the literature has seen debates about the importance for macroeconomic fluctuations of shocks to the dispersion or, more generally, to the higher moments of the idiosyncratic shock distributions that firms draw from, mediated through various physical or financial frictions. Examples of this debate are Bachmann and Bayer (2013a) and Bachmann and Bayer (2013b) versus Bloom (2009) and Bloom et

with procyclically disperse (normalized) investment levels. As shown in Bachmann and Bayer (2013a) this is strong and novel evidence for a nonconvex capital adjustment cost friction in the capital adjustment process.

${ }^{5}$ Higson, Holly, and Kattuman (2002), in contrast, finds that the skewness of sales growth in U.S. publicly traded firms is countercyclical, its kurtosis procyclical. Interestingly, Guvenen, Ozkan, and Song (2012) establishes for labor income risk on the household side that its countercyclical behavior is mainly showing up in the third, rather than the second moment.

${ }^{6}$ Bachmann, Elstner, and Sims (2013) provides some counter-evidence and Bachmann and Moscarini (2012) provides a counter-example to this view. 
al. (2012) on the importance of risk shocks propagated through physical production factor adjustment frictions, or Bachmann, Born, Elstner, and Grimme (2013) versus Vavra (2014) on the importance of risk shocks for monetary policy. ${ }^{7}$ At the end of the day, all these researchers use indirect data on cross-sectional moments to calibrate (or estimate) risk shocks and their strength. The choice of data moments invariably influences the calibration results and the importance conclusions that these researchers draw. ${ }^{8}$ None of these papers, however, to the best of our knowledge, use independent, model- and econometrics-free information about firms' expectations to measure surprises at the firm-level. Our paper provides this information. ${ }^{9}$

The remainder of this paper is structured as follows. The next section introduces the IFO-IS and defines the investment expectation errors. Section 3 reports summary statistics for the pooled (long-run) distributions of these expectation errors. Section 4 presents the stylized facts for the business cycle behavior of the mean, the dispersion, the skewness and the kurtosis of firm-specific investment surprises. Section 5 compares cross-sectional dispersion measures of investment innovations with the cross-sectional average and standard deviation of the individual-by-firm time series volatility of investment innovations. Section 6 concludes. Details and robustness checks are relegated to various appendices.

\section{Description of the Sample}

\subsection{The IFO Investment Survey}

The IFO Investment Survey is carried out twice a year and we have access to the micro data since 1970. Due to delays in the disclosure procedures at the IFO-IS our sample goes to 2010. The survey covers firms form the West German manufacturing sector and mining. The average number of respondents is roughly 3,000 at the beginning of the sample; it declines to 1,500 towards the end. The participating firms provide quantitative information

\footnotetext{
${ }^{7}$ Other examples are Arellano, Bai, and Kehoe (2012), Christiano, Motto, and Rostagno (2014) and Gilchrist, Sim, and Zakrajsek (2010) on the importance of risk shocks mediated through financial frictions. A sceptical voice here is Chugh (2012).

${ }^{8}$ An interesting example in the literature is given by how Cooper and Haltiwanger (2006) and Khan and Thomas (2008) reach their conclusions about the standard deviation of idiosyncratic firm-level profitability shocks: the latter uses the investment rate histogram in U.S. plant-level manufacturing data (publicized by the former), and the former uses direct profit data for the same firms, with vastly different results. Idiosyncratic firm-level profitability shocks are an order of magnitude stronger in Cooper and Haltiwanger (2006), compared to Khan and Thomas (2008).

${ }^{9}$ It bears repeating that, since we only have expectations about endogenous variables at our disposal and no subjective uncertainty around these expectations are available, our results still need to be interpreted through the lens of a structural model, but they improve on the literature in the sense that the expectation part of the innovation is directly disciplined by the data.
} 
(in Euro) about their investment plans for the current and upcoming year. Investment expenditures comprise expenditures for equipment and structures. Survey participants also provide quantitative information concerning their sales and employment. For these variables, however, they do not report expectations. The IFO institute aims at high-level management personnel at the firms as survey respondents.

Firms are asked in the spring of each year about their investment plans for the current year. In the fall, firms are asked about their investment expectations for the current and the upcoming year. Thus, we have for each firm and year three different investment expectations with different expectation horizons: the expectation from the fall preceding a given year, Expectation ${ }_{i, t}^{l o n g}$, the spring, Expectation ${ }_{i, t}^{\text {med }}$, and the fall expectations in a given year, Expectation short. In addition, firms report their actual investment expenditures of the preceding calendar year in the spring and in the fall surveys denoted by Realization spring $_{i, t}$ and Realization fall $_{i, t}$. Figure 1 illustrates the timing in the IFO-IS.

Figure 1: Firm Investment Expectations and Realizations in the IFO-IS - Timing

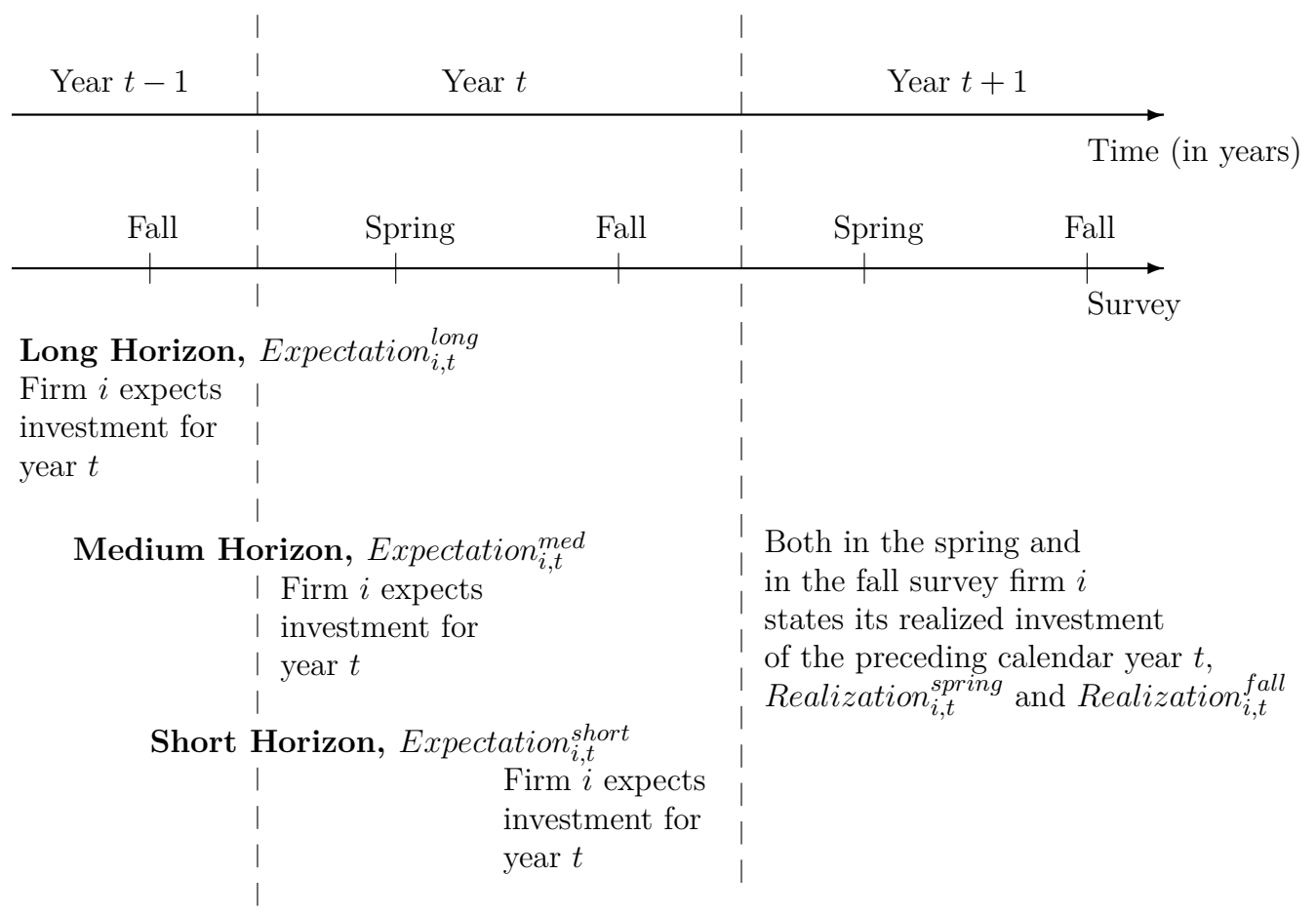

The total (nominal) investment expenditures in the IFO-IS comprise roughly and on average 40 percent of the total (nominal) manufacturing (plus mining) investment expenditures according to data from the German Federal Statistical Office. 


\subsection{Definition of Investment Innovations and Data Treatment}

We define the (percentage) expectation error of firm $i$ in year $t$ as the log difference of the realized investment expenditures in year $t$ and the predicted investment expenditures for year $t::^{10}$

$$
E E_{i, t}^{k}=\log \text { Realization }_{i, t}^{\text {mean }}-\log \text { Expectation }_{i, t}^{k},
$$

where the length of the expectation horizon is denoted by $k=\{$ short, med,long $\}$. Given the three expectation horizons, we end up with three types of expectation errors. We denote the first one by $E E_{i, t}^{\text {long }}$. It uses as expectation the firms' investment plans from the fall of the previous year $t-1$. The second series of investment expectation errors, denoted by $E E_{i, t}^{\text {med }}$, uses the firm expectation given in the spring of the current year $t$. The last expectation error type uses the fall prediction of the current year $t$. It is denoted by $E E_{i, t}^{\text {short }}$. For a subset of firms the investment realization uttered in the spring and the fall differ. In this case we use, in the baseline empirical specification, the average of both statements as Realization $_{i, t}=$ Realization $_{i, t}^{\text {mean }}=0.5 *\left(\right.$ Realization $_{i, t}^{\text {spring }}+$ Realization $\left._{i, t}^{\text {fall }}\right)$.

To construct our baseline sample we drop all firm-year observations where the spring and fall realized investment data differ by at least 10 percent. There are two interpretations of this discrepancy: reporting error; or in the fall survey the respondents have additional information available that they did not have in the spring survey. In the baseline empirical specification, we take on the first interpretation, eliminate small and random reporting errors by averaging the two investment numbers and simply ignore firms with large discrepancies. Of the remaining firm-year observations, then 37.8 percent continue to have a (small) discrepancy between the spring and fall realized investment data with an average percentage difference of 1.3 percent. In Appendix A we pursue the other interpretation, define Realization ${ }_{i, t}=$ Realization $_{i, t}^{\text {fall }}$ and include all firm-year observations regardless of consistency between the spring and the fall data, with unchanged results.

In the next data treatment step, we drop investment surprise outliers, leaving out firmyear observations smaller than the 1st percentile and larger than the 99th percentile of the corresponding year. Appendix A reports results for the whole sample with no data treatment.

It is from these baseline samples - they are, of course, slightly different across the three types of investment surprises with different expectations horizons - that we compute statistics about the long-run and the business cycle behavior of the distributions of these investment surprises.

\footnotetext{
${ }^{10} \mathrm{We}$ also compute percentage expectation errors by dividing the difference of the realized and predicted investment expenditures by the average of the realized and predicted investment expenditures without much change to our results.
} 
The possible concern with using the industry representation of the IFO-IS would be that our results lack a representative industry composition, when compared to the West German manufacturing aggregate. We address these concerns in Appendix B, where we use investment and firm distributions by two-digit manufacturing industries from national data to reweight the IFO-IS observations in such a way as to make them industry-representative. The results are essentially unchanged.

Finally, in order to take into account possible cyclical selection effects, we carry out, in Appendix C, our baseline analysis on the sample of firm-year observations that belong to firms which in the baseline sample have at least twenty years of observations of investment expectation errors. This leaves - depending on the expectation horizon - roughly twenty percent of the original sample. The results are again robust. ${ }^{11}$

\subsection{A First Look at the Data}

In the upper panel of Figure 2 we depict the growth rate (differences of the natural logarithm) of IFO-IS aggregate nominal investment expenditures in manufacturing and mining together with the official time series for these combined sectors and West Germany provided by the Federal Statistical Agency. We show the growth rate for both the whole sample with all firm-level observations and our baseline sample without outliers and potentially inconsistent realization answers. In addition, we plot the recession dates in Germany as determined by the Sachverständigenrat, the so-called Council of Economic Experts (see Sachverständigenrat (2009), p. 261), the functional equivalent of the Council of Economic Advisors to the President in the U.S. Shaded regions display the five recessions since 1970.

The correlation between the growth rate of IFO-IS investment in the whole sample and the growth rate of the nominal West German manufacturing investment from the official data is 0.84 , while the correlation between the growth rates in our baseline sample and the official investment growth rates is even slightly higher, 0.86. This means that the IFO-IS represents well the area of economic activity it is supposed to represent.

The lower panel of Figure 2 presents the novel business cycle fact documented by Bachmann and Bayer (2013a) in a somewhat different way: the cross-sectional standard deviation of firm-level investment rates is mildly procyclical. We define firm-level investment rates as either the ratio of investment expenditures of firm $i$ in period $t$ over the sales of that firm in the same period (left lower panel), or as the ratio of investment expenditures over the number of employees (right lower panel). ${ }^{12}$ The IFO-IS confirms the finding of Bachmann and Bayer

\footnotetext{
${ }^{11}$ Of course, ideally, we would like to use only those firms that are present in the data for all 40 years, but the sample would simply be too small in this case.

${ }^{12}$ The IFO-IS does not contain information about firm-level capital stocks. We, therefore, use sales and
} 
(2013a), which is based on the USTAN data base from the Deutsche Bundesbank. USTAN is a detailed and extensive balance sheet database for German firms (for details, see Bachmann and Bayer (2013a)). For the baseline sample both the sales- and the employment-normalized definitions of investment dispersion feature an unconditional correlation coefficient with the cyclical component of manufacturing investment of, respectively, 0.53 and 0.43 . The cyclical component of manufacturing investment is defined as percentage deviations of manufacturing investment from a Hodrick-Prescot (HP) filter with a smoothing parameter $100 .{ }^{13}$ This means that the investment realization data in the IFO-IS are consistent with the micro data of an independent balance-sheet-based data set from the Bundesbank.

\section{Summary Statistics for the Pooled Cross-Section}

The long-run distributional properties of investment surprises are summarized in Table 1 (and Figure 3 in Appendix D, which displays the corresponding histograms against Gaussian distributions with the same mean and variance). We pool all firm-year observations of the baseline sample and then compute distributional summary statistics for the resulting longrun distribution of investment surprises. Table 1 shows those statistics that the stochastic steady state distribution of investment surprises in a heterogeneous-firm model would have to be calibrated to in order for the model to match the micro data at least on average.

The first noteworthy feature of these investment surprise distributions is that, perhaps unsurprisingly, firms get better over time at forecasting their total annual investment, as new information on actual investment during the year comes in: the mean of the absolute expectation error declines from roughly 55 percent to approximately 28 percent between the two extreme expectation horizons. The declining standard deviation across the expectation horizons tells a similar tale.

The second noteworthy feature is that there is some evidence that the investment surprise distribution is not Gaussian, perhaps reflecting Non-Gaussianity of the underlying exogenous shock distribution. While there is no evidence of substantial skewness, we find excess kurtosis, i.e., fat tails. Kurtosis numbers rang from 4.2 to 5.9, and are decreasing in the expectation horizon. Formal tests for normality in the last two rows of Table 1 confirm the Non-Gaussianity of the investment surprise distribution: the p-values of the JarqueBera and Kolmogoroff-Smirnov tests are essentially zero and thus reject the null hypothesis of normality.

employment to normalize the investment numbers.

${ }^{13}$ The unconditional correlation coefficients of both measures of investment dispersion and the cyclical component of manufacturing production are, respectively 0.31 and 0.18 . 
Figure 2: A First Look at IFO-IS and National Accounts Data

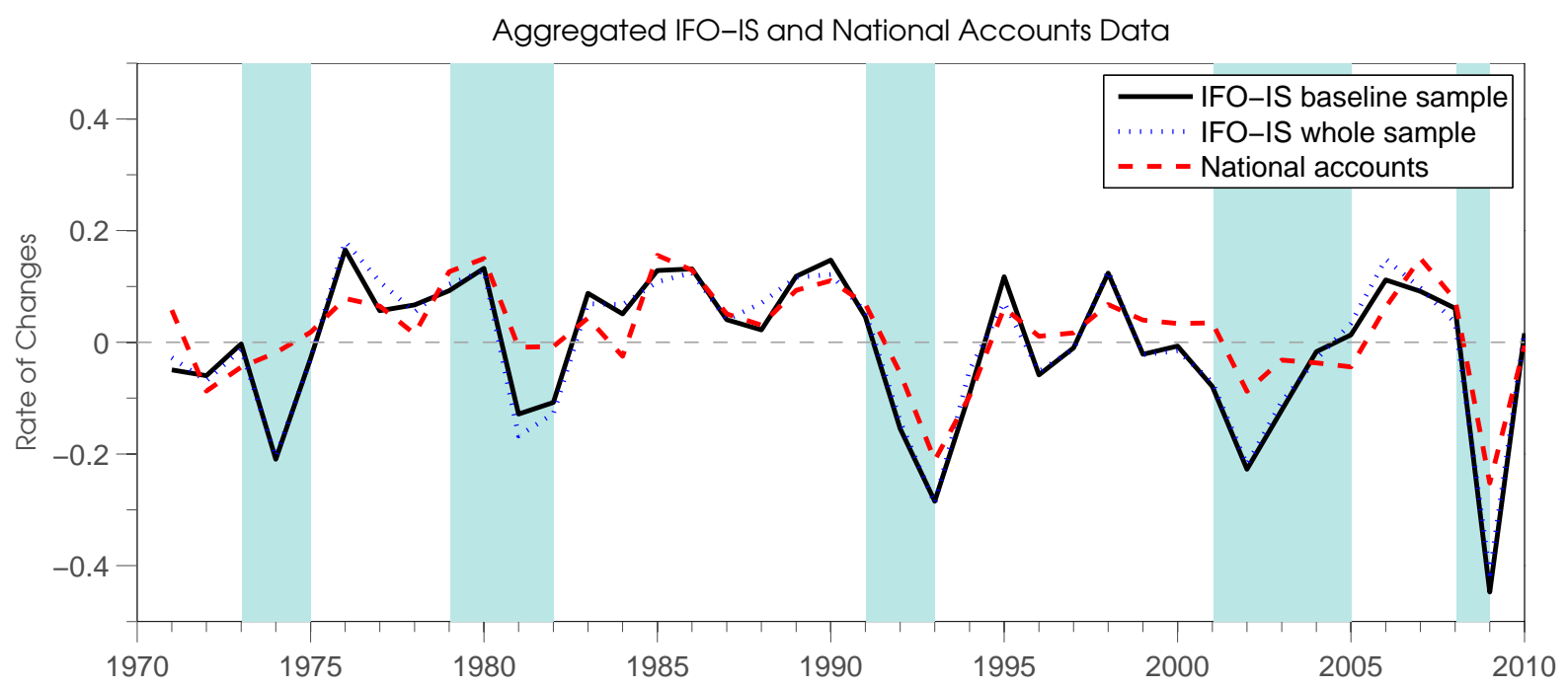

A: Investment Dispersion and the Business Cycle

B: Investment Dispersion and the Business Cycle

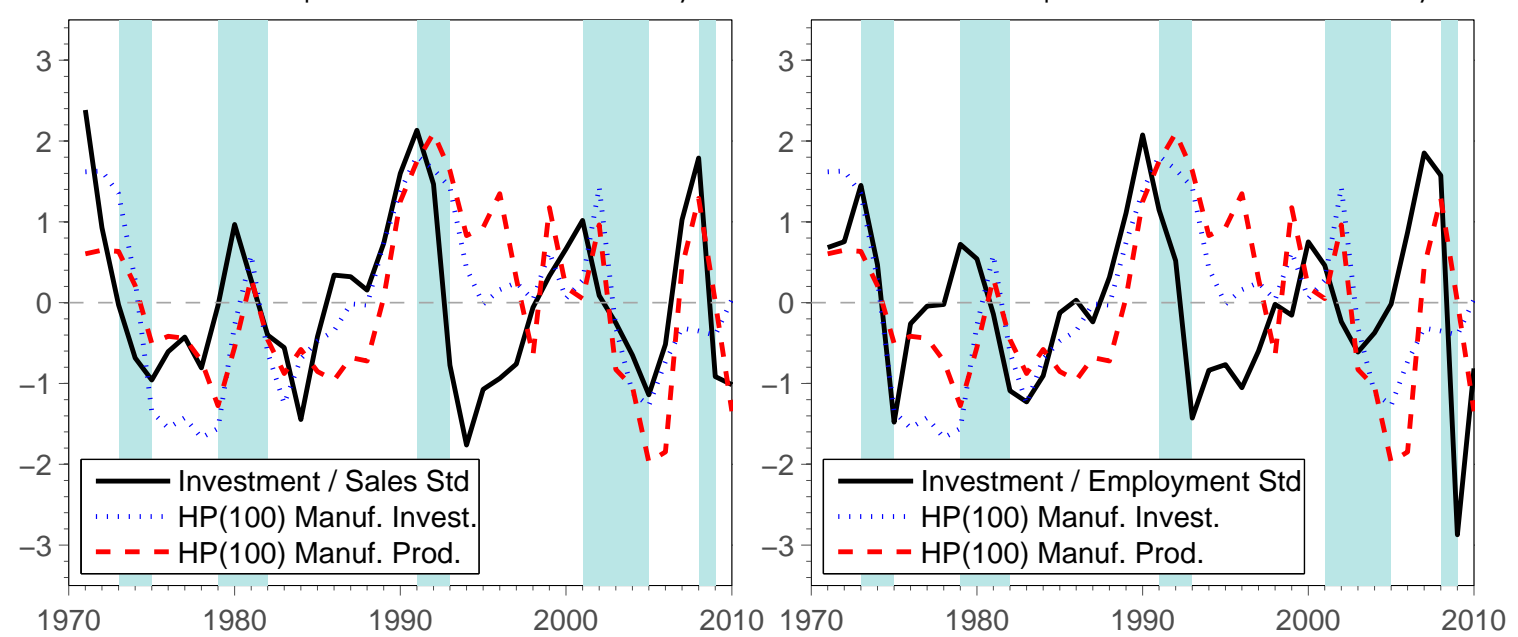

Notes: In the upper panel we depict the growth rate (ln-differences) of IFO-IS aggregate nominal investment expenditures in manufacturing and mining, both for the baseline sample (black solid line) and the whole IFO-IS (blue dotted line), together with the growth rate of the nominal West German manufacturing (plus mining) investment expenditures from the Federal Statistical Agency (red dashed line). The lower left panel displays the linearly detrended and demeaned cross-sectional standard deviation of firm-level investment divided by firm-level sales (black solid line), computed on the baseline sample, together with the HP(100)filtered natural logarithm of the West German nominal manufacturing (plus mining) investment expenditures (blue dotted line) and the HP(100)-filtered natural logarithm of the manufacturing real production index (red dashed line). For better readability, all three series are normalized by their time series standard deviation. The lower right panel does the same, only with firm-level investment divided by firm-level employment. The sample period is 1970 to 2010. Shaded regions show recessions as dated by the Sachverständigenrat (see Sachverständigenrat (2009), p. 261): II/1973 - II/1975, IV/1979 - IV/1982, I/1991 - III/1993, I/2001 $\mathrm{II} / 2005$ and I/2008 - II/2009. 
Table 1: Summary Statistics - Pooled Cross-Section of Investment Innovations

\begin{tabular}{l|ccc}
\hline Statistics & $E E_{i, t}^{\text {long }}$ & $E E_{i, t}^{\text {med }}$ & $E E_{i, t}^{\text {short }}$ \\
\hline Obs & 47,224 & 52,592 & 54,673 \\
Mean & 0.035 & -0.011 & 0.009 \\
Std.Dev. & 0.744 & 0.591 & 0.420 \\
Skewness & 0.043 & -0.139 & -0.083 \\
Kurtosis & 4.216 & 4.637 & 5.874 \\
& & & \\
Percentiles & & & \\
5th & -1.216 & -1.038 & -0.693 \\
10th & -0.851 & -0.700 & -0.446 \\
25th & -0.360 & -0.299 & -0.162 \\
50th & 0.008 & 0.000 & 0.000 \\
75th & 0.431 & 0.290 & 0.184 \\
90th & 0.924 & 0.673 & 0.471 \\
95th & 1.311 & 0.967 & 0.698 \\
& & & \\
Mean of Abs $\left(E E_{i, t}^{k}\right)$ & 0.546 & 0.424 & 0.280 \\
& & & \\
p-values of & & & \\
Jarque-Bera Test & 0.00 & 0.00 & 0.00 \\
Kolmogoroff-Smirnov Test & 0.00 & 0.00 & 0.00 \\
\hline
\end{tabular}

Notes: The table provides a summary of the pooled (across firm-years) distributions of $E E_{i, t}^{\text {long }}, E E_{i, t}^{\text {med }}$ and $E E_{i, t}^{s h o r t}$. The row 'Mean of $A b s\left(E E_{i, t}^{k}\right)$ ' displays the mean of the absolute values of $E E_{i, t}^{k}$. The last two rows show formal test results about the normality of the samples of investment innovations. 


\section{Investment Innovations and the Business Cycle}

In this section, we analyze, through the documentation of standard second moment time series statistics, the business cycle behavior of the first four cross-sectional moments of the investment innovation cross-section: mean, dispersion, skewness and kurtosis. ${ }^{14}$ The crosssectional average of investment innovations is clearly procyclical, while the cross-sectional dispersion of investment innovations is countercyclical. The cross-sectional skewness and kurtosis of investment innovations are largely acyclical.

Before we study the business cycle behavior of these cross-sectional moments of the investment expectation error distribution, it is, however, instructive to investigate how different (or similar) the time series for the various moments behave across the three expectation horizons. In other words, is the time series behavior of the cross-sectional average of the $E E_{i, t}^{k}, M E A N E E_{t}$, similar whether we base the underlying expectation error on the long time horizon (a little over a year), the medium time horizon (a little over half a year) or the short time horizon (roughly a quarter)? The same can be asked for the time series of the higher cross-sectional moments. This is interesting, because it provides a sense of robustness and consistency for our results. Table 2 addresses this question in a simple way by documenting, for the time series of each cross-sectional moment, the time series correlation coefficients across the three expectation horizons.

Interestingly, the second moments, the measures of firm-level risk, DISPEE $E_{t}$ and $S T D E E_{t}$, display the strongest correlation across expectation horizons, followed by the first moment. In contrast, kurtosis and especially skewness display much less consistency across expectation horizons, which might be at least suggestive of the fact that there is little in terms of systematic time series movements of these higher moments in the data, which, in turn, is confirmed in our business cycle analysis below.

\subsection{Cross-Sectional Means of Investment Innovations}

We start our business cycle analysis with the cross-sectional mean. We compute for each year and each expectation horizon the average of all $E E_{i, t}^{k}$. We denote the newly created variable by $M E A N E E_{t}^{k}$. To gauge the cyclical properties of $M E A N E E_{t}^{k}$, we linearly detrend and demean it and correlate it with various cyclical aggregate activity variables for the German manufacturing sector. We use West German nominal investment expenditures made in the manufacturing and the mining sector, an index of manufacturing real production, i.e., a measure of gross output, and an index of manufacturing real value added. To extract cyclical components from these variables we use year-over-year growth rates (differences in

\footnotetext{
${ }^{14}$ Appendix E provides time series graphs for these moments for the three expectation horizons, together with German recessions as dated by the Sachverständigenrat (see Sachverständigenrat (2009)).
} 
Table 2: Correlations Between the Time Series of Various Moments of Investment Innovations, Based on the Three Expectation Horizons

\begin{tabular}{l|ccc}
\hline Moment of $E E_{i, t}$ & $\begin{array}{c}\text { Correlation between } \\
\text { moment of } \\
E E_{i, t}^{\text {long }}, E E_{i, t}^{\text {med }}\end{array}$ & $\begin{array}{c}\text { Correlation between } \\
\text { moment of } \\
E E_{i, t}^{\text {long }}, E E_{i, t}^{\text {short }}\end{array}$ & $\begin{array}{c}\text { Correlation between } \\
\text { moment of } \\
E E_{i, t}^{\text {med }}, E E_{i, t}^{\text {short }}\end{array}$ \\
\hline MEANEE $E_{t}$ & $0.801^{* * *}$ & $0.309^{* * *}$ & $0.459^{* * *}$ \\
DISPEE & $0.794^{* * *}$ & $0.566^{* * *}$ & $0.630^{* * *}$ \\
$S K E W E E_{t}$ & $0.431^{* * *}$ & 0.248 & 0.151 \\
KURTEE $E_{t}$ & $0.443^{* * *}$ & $0.398^{* *}$ & $0.540^{* * *}$ \\
$S T D E E_{t}$ & $0.683^{* * *}$ & $0.616^{* * *}$ & $0.783^{* * *}$ \\
$D I S P S T D E E_{t}$ & $0.467^{* * *}$ & $0.486^{* * *}$ & $0.803^{* * *}$ \\
\hline
\end{tabular}

Notes: This table provides correlation coefficients between $M E A N E E_{t}^{\text {long }}$ and $M E A N E E_{t}^{\text {med }}$ (first row, first column), $M E A N E E_{t}^{\text {long }}$ and $M E A N E E_{t}^{\text {short }}$ (first row, second column), and $M E A N E E_{t}^{\text {med }}$ and $M E A N E E_{t}^{\text {short }}$ (first row, third column). $M E A N E E_{t}^{k}$ is the cross-sectional average of all $E E_{i, t}^{k}$ at time $t$ for expectation horizon $k$. Rows two to four compute the same correlations for, respectively, the crosssectional standard deviations, skewness and kurtosis of the $E E_{i, t}^{k}$. Rows five and six compute the same correlations for the cross-sectional average and standard deviations of a firm-individual volatility measure based on $E E_{i, t}^{k}$ (see Section 5 for details). All time series are linearly detrended and demeaned. To test for significance of the time-series correlations (in a one-sided test) we use a nonparametric overlapping block bootstrap with a four-year window and with 10,000 replications. *** denotes $1 \%$ significance, ${ }^{* *} 5 \%$ significance and $* 10 \%$ significance.

natural logarithms) and, alternatively, an $\mathrm{HP}(100)$-filter applied to the natural logarithm of these time series. To test for significance of the time-series correlations coefficients, we use a nonparametric overlapping block bootstrap of four-year windows with 10,000 replications.

Table 3 summarizes the results. The main finding is that $M E A N E E_{t}^{k}$ is procyclical for all expectation horizons. We find the highest correlation between the expectation errors over the long expectation horizon, $M E A N E E_{t}^{l o n g}$, and the growth rates of the activity variables. In all cases, the pairwise correlation between $M E A N E E_{t}^{k}$ and the activity variables is larger for the growth rates than for the cyclical components extracted with an HP-filter. This is not surprising as an investment innovation is naturally more correlated with a first difference than a level variable. The penultimate row displays the time-series volatility of the various $M E A N E E_{t}^{k}$, which is fairly sizeable, 0.144 for $M E A N E E_{t}^{l o n g}$, but declining with the horizon for the investment expectation.

The last row of Table 3 reports a regression estimate of the $M E A N E E_{t}^{k}$ on a constant and a recession indicator. For the latter, we use the definition proposed by Bloom et al. (2012), and take the share of quarters in that year that were defined as a recession - in our 
case by the German Sachverständigenrat (see Sachverständigenrat (2009), p. 261). We find that $M E A N E E_{t}^{\text {long }}$ decreases by 14.6 percent during a recession year, implying that in an average recession realized investment is 14.6 percent lower than was expected a year before. The recession indicator is significant at the one percent significance level for $M E A N E E_{t}^{\text {long }}$ and $M E A N E E_{t}^{m e d}$.

\subsection{Cross-Sectional Dispersion of Investment Innovations}

The results for the cross-sectional dispersion of investment surprises, DISPE $E_{t}^{k}$, are shown in Table 4. It complements the results in the aforementioned literature about the countercyclicality of the dispersion of various firm-level outcome variables, that has often been interpreted as evidence of countercyclical idiosyncratic firm-level risk shocks; it complements these results with evidence that the cross-sectional dispersion of true investment surprises is also countercyclical, and higher in recessions. This at least suggests that the countercyclicality of the dispersion of firm-level outcome variables is indeed the result of countercyclical firm-level risk. Table 4 makes these points both when using the cross-sectional standard deviation as a measure of dispersion (left panel) and when using the cross-sectional interquartile range (right panel). ${ }^{15}$

The last two rows of Table 4 report, respectively, the time-series average of the raw, i.e., undetrended and undemeaned, DISPEE $E_{t}^{k}$, as a measure of the average cross-sectional dispersion of investment innovations, and the time-series coefficient of variation of DISPEE $E_{t}^{k}$, as a measure of the strength of dispersion fluctuations. DISPE $E_{t}^{k}$ declines with the expectation horizon just as the mean of $A b s\left(E E_{i, t}^{k}\right)$ in Table 1 does.

The first column of Table 4 gives also information about the percentage standard deviations of the growth rates and $\mathrm{HP}(100)$-filtered cyclical components of, respectively, investment, production and value added in the German manufacturing sector. It is clear that the volatility of all dispersion measures of investment innovations is sizeable - it ranges from 6.4 to 11 percent - and comparable to the size of investment fluctuations themselves (9.2 and 10 percent), and considerably larger than output fluctuations (between 3.9 and 5 percent). This suggests that distributional fluctuations, and, if one is inclined to interpret dispersion fluctuations as exogenous risk fluctuations, these risk fluctuations, as used by many researchers in the recent literature may well have a similar magnitude as first-moment aggregate fluctuations over the business cycle.

\footnotetext{
${ }^{15}$ Appendix $\mathrm{F}$ shows that the dispersion of investment surprises is also countercyclical at a more disaggregated level, i.e., for most 2-digit manufacturing industries and for all five employment-size quantiles. The countercyclicality of dispersion in the aggregate is therefore unlikely to be the result of a mere composition effect where different firm types react differently to aggregate shocks or recessions.
} 
Table 3: Cross-Sectional Mean of Investment Innovations and the Business CYCLE

\begin{tabular}{|c|c|c|c|}
\hline & $M E A N E E_{t}^{l o n g}$ & $M E A N E E_{t}^{m e d}$ & $M E A N E E_{t}^{s h o r t}$ \\
\hline Years & $1971-2010$ & $1970-2010$ & $1970-2010$ \\
\hline Observations & 40 & 41 & 41 \\
\hline $\begin{array}{l}\text { Correlation with } \\
\text { growth rate of: }\end{array}$ & & & \\
\hline Investment & $0.707^{* * *}$ & $0.591^{* * *}$ & $0.435^{* * *}$ \\
\hline Production & $0.785^{* * *}$ & $0.490 * * *$ & 0.171 \\
\hline Value Added & $0.658^{* * *}$ & 0.381 & 0.230 \\
\hline $\begin{array}{l}\text { Correlation with } \\
\text { cyclical component of: }\end{array}$ & & & \\
\hline Investment & 0.152 & 0.155 & $0.248^{*}$ \\
\hline Production & $0.389^{* *}$ & 0.152 & 0.055 \\
\hline Value Added & 0.341 & 0.148 & -0.017 \\
\hline Std. Dev. & 0.144 & 0.083 & 0.031 \\
\hline Recession & $-0.146^{* * *}$ & $-0.062^{* * *}$ & -0.005 \\
\hline
\end{tabular}

Notes: This table provides correlation coefficients between $M E A N E E_{t}^{k}$ and cyclical aggregate activity variables for the German manufacturing sector. We use as activity variables the (linearly detrended and demeaned) growth rates, computed as differences in the natural logarithm, and the HP(100)-filtered log time series, of, respectively, West German nominal investment expenditures in manufacturing and mining, an index of manufacturing real production, and an index of manufacturing real value added. Data for the activity variables are from the German Federal Statistical Office. All time series based on expectation errors are linearly detrended and demeaned. To test for significance of the time-series correlations (in a one-sided test) we use a nonparametric overlapping block bootstrap with a four-year window and with 10,000 replications. $* * *$ denotes $1 \%$ significance, ${ }^{* *} 5 \%$ significance and $* 10 \%$ significance. The penultimate row displays the time-series standard deviation of the linearly detrended and demeaned $M E A N E E_{t}^{k}$. The last row reports a regression estimate of the $M E A N E E_{t}^{k}$ on a constant and a recession indicator. For the latter, we use the definition proposed by Bloom et al. (2012) and take the share of quarters in that year that were defined as a recession. We use the recession dates provided by the Sachverständigenrat (see Sachverständigenrat, 2009, p. 261): II/1973 - II/1975, IV/1979 - IV/1982, I/1991 - III/1993, I/2001 - II/2005 and I/2008 - II/2009. To test the statistical significance of the recession coefficient we use Newey-West standard errors to account for any potential serial correlation. 
Table 4: Cross-Sectional Dispersion of Investment Innovations and the Business Cycle

\begin{tabular}{|c|c|c|c|c|c|c|}
\hline & \multicolumn{3}{|c|}{ DISP $=$ Std.Dev } & \multicolumn{3}{|c|}{$\mathrm{DISP}=\mathrm{IQR}$} \\
\hline & $D I S P E E_{t}^{\text {long }}$ & $D I S P E E_{t}^{\text {med }}$ & $D I S P E E_{t}^{\text {short }}$ & $D I S P E E_{t}^{\text {long }}$ & $D I S P E E_{t}^{\text {med }}$ & $D I S P E E_{t}^{\text {short }}$ \\
\hline Years & $1971-2010$ & $1970-2010$ & $1970-2010$ & $1971-2010$ & $1970-2010$ & $1970-2010$ \\
\hline Observations & 40 & 41 & 41 & 40 & 41 & 41 \\
\hline $\begin{array}{l}\text { Correlation with } \\
\text { growth rate of: }\end{array}$ & & & & & & \\
\hline Investment, Std. Dev. $=0.092$ & $-0.551^{* * *}$ & $-0.349 * * *$ & $-0.276^{* * *}$ & $-0.594^{* * *}$ & $-0.436^{* * *}$ & $-0.242^{*}$ \\
\hline Production, Std. Dev. $=0.050$ & $-0.346^{* * *}$ & -0.151 & $-0.080^{*}$ & $-0.433^{* * *}$ & $-0.225^{* * *}$ & $-0.058^{*}$ \\
\hline Value Added, Std. Dev. $=0.049$ & $-0.213^{* *}$ & -0.075 & 0.060 & $-0.289 * * *$ & $-0.122^{* * *}$ & 0.063 \\
\hline $\begin{array}{l}\text { Correlation with } \\
\text { cyclical component of: }\end{array}$ & & & & & & \\
\hline Investment, Std. Dev. $=0.100$ & $-0.433^{* * *}$ & -0.213 & $-0.359 * *$ & $-0.479^{* * *}$ & $-0.233^{*}$ & $-0.436^{* *}$ \\
\hline Production, Std. Dev. $=0.046$ & $-0.556^{* * *}$ & $-0.261^{*}$ & $-0.315^{* *}$ & $-0.595^{* * *}$ & $-0.367^{* *}$ & $-0.347^{* *}$ \\
\hline Value Added, Std. Dev. $=0.039$ & $-0.505^{* *}$ & $-0.318^{*}$ & -0.155 & $-0.509^{* *}$ & $-0.351^{* *}$ & -0.043 \\
\hline Recession & 0.029 & $0.048^{*}$ & $0.033^{*}$ & 0.021 & 0.034 & $0.019^{* * *}$ \\
\hline Mean of raw DISPEE $E_{t}^{k}$ & 0.732 & 0.583 & 0.417 & 0.782 & 0.583 & 0.345 \\
\hline Coeff. of Variat. & 0.064 & 0.089 & 0.087 & 0.085 & 0.109 & 0.110 \\
\hline
\end{tabular}

Notes: See notes to Table 3. The explanations there hold exactly here as well, replacing $M E A N E E_{t}^{k}$ with $D I S P E E_{t}^{k}$. The last two rows report the mean of the time-series average of the raw DISPE $E_{t}^{k}$, and the time-series coefficient of variation of DISPEE $E_{t}^{k}$, defined as the ratio of the time-series standard deviation of the (detrended and demeaned) series to the time-series average of the raw series. The left panel of the table operationalizes crosssectional dispersion with the standard deviation, the right panel uses the interquartile range. The numbers in the first column after the designation of the cyclical indicators display their time-series standard deviation. 
Table 5: Cross-sectional Skewness of Investment Innovations and the Business Cycle

\begin{tabular}{|c|c|c|c|c|c|c|}
\hline & $S K E W E E_{t}^{\text {long }}$ & $S K E W E E_{t}^{\text {med }}$ & $S K E W E E_{t}^{\text {short }}$ & $K E L L E E_{t}^{l o n g}$ & $K E L L E E_{t}^{\text {med }}$ & $K E L L E E_{t}^{\text {short }}$ \\
\hline $\begin{array}{l}\text { Years } \\
\text { Observations }\end{array}$ & $\begin{array}{c}1971-2010 \\
40\end{array}$ & $\begin{array}{c}1970-2010 \\
41\end{array}$ & $\begin{array}{c}1970-2010 \\
41\end{array}$ & $\begin{array}{c}1971-2010 \\
40\end{array}$ & $\begin{array}{c}1970-2010 \\
41\end{array}$ & $\begin{array}{c}1970-2010 \\
41\end{array}$ \\
\hline $\begin{array}{l}\text { Correlation with } \\
\text { growth rate of: } \\
\text { Investment } \\
\text { Production } \\
\text { Value Added }\end{array}$ & $\begin{array}{l}0.120 \\
0.310^{* * *} \\
0.196\end{array}$ & $\begin{array}{r}-0.084 \\
0.050 \\
0.049\end{array}$ & $\begin{array}{l}0.147 \\
0.079 \\
0.005\end{array}$ & $\begin{array}{l}0.316^{* *} \\
0.445^{* * *} \\
0.378^{*}\end{array}$ & $\begin{array}{l}0.196^{*} \\
0.266 \\
0.212\end{array}$ & $\begin{array}{l}0.341^{* *} \\
0.171 \\
0.223\end{array}$ \\
\hline $\begin{array}{l}\text { Correlation with } \\
\text { cyclical component of: } \\
\text { Investment } \\
\text { Production } \\
\text { Value Added }\end{array}$ & $\begin{array}{l}-0.096 \\
-0.025 \\
-0.123\end{array}$ & $\begin{array}{l}-0.122 \\
-0.205 \\
-0.126\end{array}$ & $\begin{array}{l}0.140 \\
-0.067^{* *} \\
-0.208^{* * *}\end{array}$ & $\begin{array}{r}0.003 \\
-0.013 \\
-0.054\end{array}$ & $\begin{array}{r}0.003 \\
-0.058 \\
-0.010\end{array}$ & $\begin{array}{r}0.142 \\
-0.019 \\
-0.089\end{array}$ \\
\hline $\begin{array}{l}\text { Mean of raw } S K E W E E_{t}^{k} \\
\text { or of raw } K E L L E E_{t}^{k} \\
\text { Coeff. of Variation }\end{array}$ & $\begin{array}{l}0.098 \\
2.144\end{array}$ & $\begin{array}{r}-0.124 \\
1.497\end{array}$ & $\begin{array}{l}0.075 \\
3.499\end{array}$ & $\begin{array}{l}0.011 \\
4.291\end{array}$ & $\begin{array}{r}-0.032 \\
1.576\end{array}$ & $\begin{array}{r}0.005 \\
10.553\end{array}$ \\
\hline
\end{tabular}

Notes: See notes to Tables 3 and 4. The explanations there hold exactly here as well, replacing $M E A N E E_{t}^{k} / D I S P E E_{t}^{k}$ with $S K E W E E_{t}^{k}$ or $K E L L E E_{t}^{k}$. 


\subsection{Cross-Sectional Skewness and Kurtosis of Investment Innova- tions}

The results for the cross-sectional skewness, $S K E W E E_{t}^{k}$ and $K E L L E E_{t}^{k}$, and kurtosis, $K U R T E E_{t}^{k}$, of investment surprises are shown in Tables 5 and 6 . We use both the standard measure of skewness, the central third moment, and Kelly's skewness, based on the difference between the difference of the 90th percentile from the median and the 10th percentile from the median. With the exception of Bloom et al. (2012), the literature has not systematically investigated the time-series variation of the higher moments of cross-sectional firm-level variables (Baker and Bloom (2013) have studied this issue in a the context of stock market returns). However, like them, we find little evidence of systematic variation in the business cycle behavior of these higher moments. If anything, they are both mildly procyclical, i.e., investment innovations become slightly more asymmetric and fat-tailed in booms. However, the lag of consistency across expectation horizons, documented in Table 2 above, suggests that any consistent (in the statistical sense) correlation we find for one expectation horizon is likely to be unsystematic and not really indicative of systematic time series fluctuations of the third and fourth cross-sectional moments of investment innovations. ${ }^{16}$

\section{Individual Time-Series Volatility and Cross-Sectional Dispersion of Investment Innovations}

In this section, we follow Comin and Mulani (2006) and Davis, Haltiwanger, Jarmin, and Miranda (2006), and use an individual-by-firm time series volatility measure of investment surprises, as an alternative measure of firm-level volatility; an alternative to cross-sectionaldispersion-based measures. We compare both its cross-sectional mean ( $S T D E E_{t}^{k}$, see Table 7), a measure of the average firm-level volatility in the sample, and its cross-sectional standard deviation (DISPSTDE $E_{t}^{k}$, see Table 8), a measure of the heterogeneity of firmlevel volatility processes, to the cross-sectional standard deviation of investment innovations (see Section 4.2) and to the various business cycle indicators of aggregate manufacturing activity. Specifically, we use the following three-year rolling window standard deviation of a

\footnotetext{
${ }^{16}$ This does, of course, not mean that higher moments are not important, as shown for example by (Gourio (2013)) and (Barro, Nakamura, Steinsson, and Ursua (2013)). This simply means that they may not be changing rapidly enough at business cycle frequencies.
} 
Table 6: Cross-sectional Kurtosis of Investment Innovations and the Business CYCLE

\begin{tabular}{|c|c|c|c|}
\hline & $K U R T E E_{t}^{\text {long }}$ & $K U R T E E_{t}^{\text {med }}$ & $K U R T E E_{t}^{\text {short }}$ \\
\hline Years & 1971-2010 & 1970-2010 & 1970-2010 \\
\hline Observations & 40 & 41 & 41 \\
\hline $\begin{array}{l}\text { Correlation with } \\
\text { growth rate of: }\end{array}$ & & & \\
\hline Investment & 0.069 & $0.358^{* *}$ & 0.088 \\
\hline Production & $0.116^{* *}$ & $0.356^{* * *}$ & $0.252^{*}$ \\
\hline Value Added & -0.027 & $0.277^{* *}$ & 0.194 \\
\hline $\begin{array}{l}\text { Correlation with } \\
\text { cyclical component of: }\end{array}$ & & & \\
\hline Investment & 0.199 & 0.173 & 0.225 \\
\hline Production & 0.260 & $0.472^{* * *}$ & $0.327^{* *}$ \\
\hline Value Added & 0.007 & $0.389^{*}$ & 0.127 \\
\hline Recession & -0.023 & $-0.219^{*}$ & -0.060 \\
\hline Mean of raw $K U R T E E_{t}^{k}$ & 4.163 & 4.507 & 5.659 \\
\hline Coeff. of Variation & 0.063 & 0.088 & 0.092 \\
\hline
\end{tabular}

Notes: See notes to Tables 3 and 4 . The explanations there hold exactly here as well, replacing $M E A N E E_{t}^{k}$ / DISPEE $E_{t}^{k}$ with KURTEE $E_{t}^{k}$.

firm's investment surprises: ${ }^{17}$

$$
S T D E E_{i, t}^{k}=\sqrt{\frac{1}{3} \sum_{j}\left(E E_{i, t+j}^{k}-\overline{E E}_{i, t}^{k}\right)^{2}}
$$

where $\overline{E E}_{i, t}^{k}$ is the average of $E E_{i, t+j}^{k}$ for $j=\{-1,0,1\}$.

Like DISPEE $E_{t}^{k}, S T D E E_{t}^{k}$ (the cross-sectional mean of STDE $E_{i, t}^{k}$ ) and DISPSTDEE $E_{t}^{k}$ (the cross-sectional standard deviation of $S T D E E_{i, t}^{k}$ ) are countercyclical, as Tables 7 and 8 show. ${ }^{18}$ They are both fairly strongly positively correlated with their corresponding DISPEE $t_{t}^{k}$

\footnotetext{
${ }^{17}$ See for a robustness check with a five-year rolling window standard deviation Appendix G. Using a seven-year rolling window would have left us with too few data.

${ }^{18}$ Appendix F shows that both $S T D E E_{t}^{k}$ and DISPSTDE $E_{t}^{k}$ are also countercyclical at a more disaggregated level, i.e., for most 2-digit manufacturing industries and for all five employment-size quantiles.
} 
measure. This raises the question whether the cyclical behavior or the cross-sectional dispersion of investment innovations is mainly driven by fluctuations in the average firm-level volatility in the sample or merely by changes in the heterogeneity of firm-level volatility processes. In other words, are cyclical fluctuations in the cross-sectional dispersion of firm-level variables really the outcome of time-varying average firm-level volatility or risk, as many papers in the literature have assumed?

Table 9 is an attempt to shed some light on this issue. It displays the results of simple OLS regressions of the time series of DISPEE $E_{t}^{k}$ on the time series of $S T D E E_{t}^{k}$ and $D I S P S T D E E_{t}^{k}$, both jointly and separately. Unsurprisingly, in the separate regressions both $S T D E E_{t}^{k}$ and DISPSTDE $E_{t}^{k}$ have highly significant coefficients and almost equal explanatory power, as measured by the $R^{2}$, between 0.4 and 0.6 , depending on the horizon of the underlying investment expectation. However, the $R^{2}$ from $S T D E E_{t}^{k}$ individually is uniformly somewhat higher than the $R^{2}$ from DISPSTDE $E_{t}^{k}$ individually, and in the regressions with both variables as regressors it is $S T D E E_{t}^{k}$ that "drives out" DISPSTDE $E_{t}^{k}$ and not vice versa. DISPSTDE $E_{t}^{k}$ becomes insignificant in all three horizon specifications and the $R^{2}$ in the regression with two regressors is essentially unchanged relative to the specification with $S T D E E_{t}^{k}$ individually. These results provide some justification for the practice in the literature to use time-varying dispersion measures as proxies for firm-individual volatility processes.

This practice is also supported by the fact that $D I S P E E_{t}^{k}$ and $S T D E E_{t}^{k}$ have very similar time-series coefficients of variation (see the last rows of Tables 4 and 7 , respectively), which means that a calibration to either measure of risk or volatility shocks in a structural model would yield the same relative strength of these risk shocks, relative to, for instance, first-moment TFP shocks (see Bachmann and Bayer (2013b) for a quantitative exploration of the time-series coefficient of variation for the importance of risk shocks for aggregate dynamics). ${ }^{19}$ These time-series coefficients of variation also suggest, just as with DISPE $E_{t}^{k}$, that the aggregate volatility of all firm-individual volatility measures of investment innovations is sizeable (between 6.7 and 9.8 percent) and comparable to the size of investment fluctuations themselves (9.2 and 10 percent) and larger than output fluctuations (between 3.9 and 5 percent). Risk fluctuations may thus have a similar magnitude as aggregate fluctuations over the business cycle.

In terms of long-run behavior, however, Tables 4, 7 and 8, in their penultimate rows, also show that the average level of idiosyncratic risk is likely overestimated by the DISPEE $E_{t}^{k}$

\footnotetext{
${ }^{19}$ We want to re-emphasize that our results do not shed light on the question of exogeneity of risk fluctuations, they simply provide guidance to a researcher on how to calibrate a structural model that already contains risk fluctuations as exogenous shocks.
} 
measures. The time-series average of DISPEE $E_{t}^{\text {long }}$, for instance, is 0.732 , compared to the time-series average of $S T D E E_{t}^{\text {long }}$ at 0.414 . The explanation lies in the time series average of DISPSTDE $E_{t}^{\text {long }}$ being 0.303 , which means that part of the measured crosssectional dispersion of investment surprises is simply the results of firms being different in their firm-individual risk. The assumption of an ergodic environment, where the crosssectional standard deviation of investment surprises is the same as the average firm-individual standard deviation appears to be inconsistent with the data. Finally, Tables 7 and 8 show that both the average firm-level volatility and its heterogeneity decline with the expectation horizon, just as DISPEE $E_{t}^{k}$ does.

Table 7: Cross-sectional Mean of the Individual Volatility of Investment Innovations AND THE Business CyCLE

\begin{tabular}{|c|c|c|c|}
\hline & $S T D E E_{t}^{l o n g}$ & $S T D E E_{t}^{m e d}$ & $S T D E E_{t}^{\text {short }}$ \\
\hline Years & 1972-2009 & 1971-2009 & 1971-2009 \\
\hline Observations & 38 & 39 & 39 \\
\hline \multicolumn{4}{|l|}{$\begin{array}{l}\text { Correlation with } \\
\text { growth rate of: }\end{array}$} \\
\hline Investment, Std. Dev. $=0.092$ & $-0.526^{* * *}$ & $-0.317^{* *}$ & $-0.331^{* * *}$ \\
\hline Production, Std. Dev. $=0.050$ & $-0.442^{* * *}$ & -0.102 & $-0.255^{* * *}$ \\
\hline Value Added, Std. Dev. $=0.049$ & $-0.443^{* * *}$ & -0.108 & $-0.210^{* * *}$ \\
\hline \multicolumn{4}{|l|}{$\begin{array}{l}\text { Correlation with } \\
\text { cyclical component of: }\end{array}$} \\
\hline Investment, Std. Dev. $=0.100$ & -0.245 & -0.176 & -0.348 \\
\hline Production, Std. Dev. $=0.046$ & $-0.489^{* * *}$ & -0.228 & $-0.417^{* *}$ \\
\hline Value Added, Std. Dev. $=0.039$ & $-0.472^{* * *}$ & $-0.290^{*}$ & $-0.244^{*}$ \\
\hline Recession & $0.037^{* * *}$ & $0.035^{*}$ & $0.021^{* *}$ \\
\hline \multicolumn{4}{|l|}{ Correlation with } \\
\hline $\begin{array}{l}\text { cross-sectional dispersion: } \\
\text { DISPEE } E_{t}^{\text {long }}\end{array}$ & $0.665^{* * *}$ & & \\
\hline$D I S P E E_{t}^{\text {med }}$ & & $0.800^{* * *}$ & \\
\hline$D I S P E E_{t}^{\text {short }}$ & & & $0.780^{* * *}$ \\
\hline Mean of raw $S T D E E_{t}^{k}$ & 0.414 & 0.339 & 0.230 \\
\hline Coeff. of Variation & 0.067 & 0.098 & 0.081 \\
\hline
\end{tabular}

Notes: See notes to Tables 3 and 4 . The explanations there hold exactly here as well, replacing $M E A N E E_{t}^{k}$ / DISPEE $t_{t}^{k}$ with $S T D E E_{t}^{k}$. The panel 'Correlation with cross-sectional dispersion' shows the pairwise correlation coefficients between $S T D E E_{t}^{k}$ and $D I S P E E_{t}^{k}$, the latter denoting the (linearly detrended and demeaned) cross-sectional standard deviations of the investment innovations. 
Table 8: Cross-Sectional Standard Deviation of the Individual Volatility of Investment Innovations And the Business CyCle

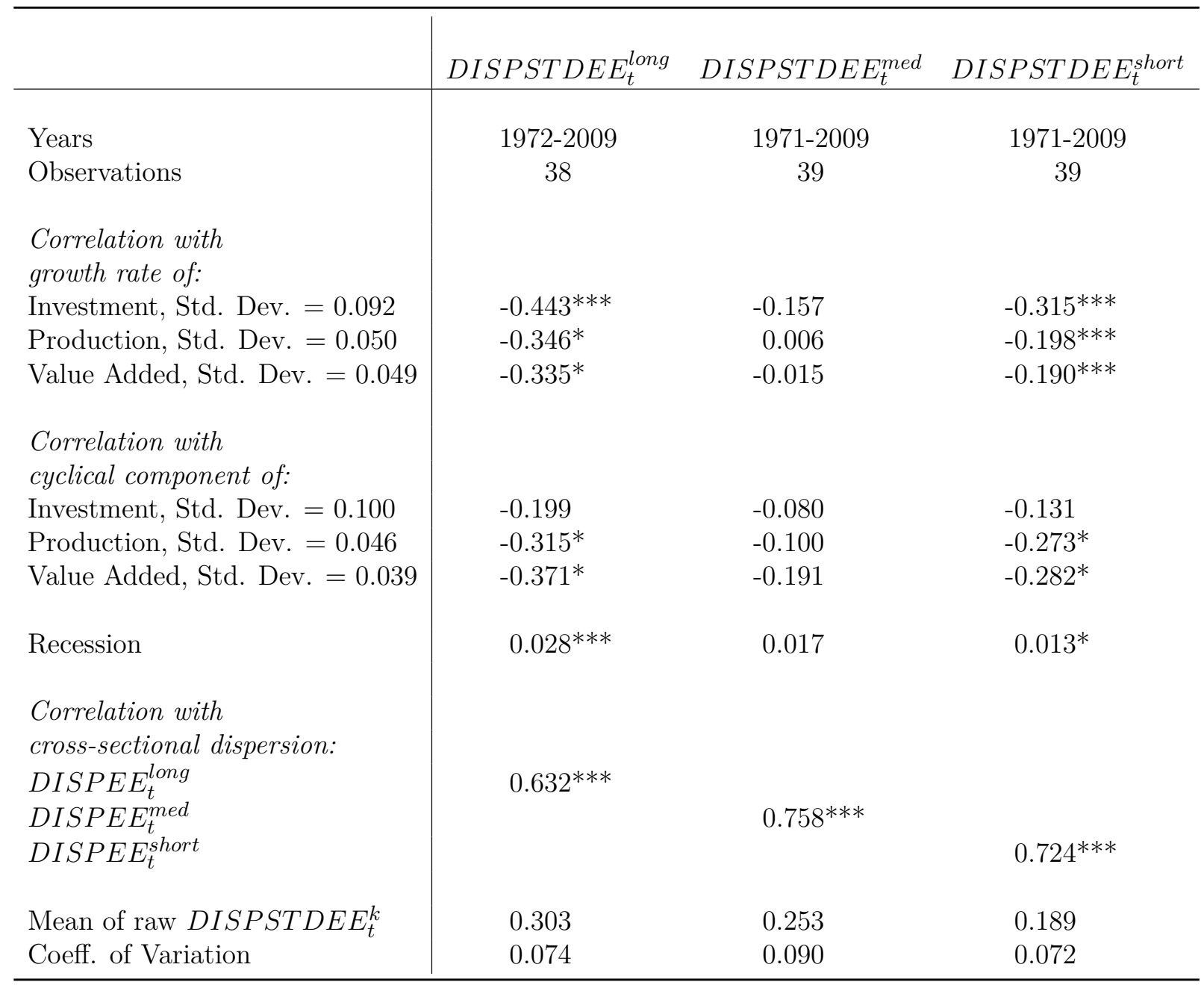

Notes: See notes to Tables 3 and 4. The explanations there hold exactly here as well, replacing $M E A N E E_{t}^{k} /$ $D I S P E E_{t}^{k}$ with DISPSTDE $E_{t}^{k}$. The panel 'Correlation with cross-sectional dispersion' shows the pairwise correlation coefficients between DISPSTDE $E_{t}^{k}$ and DISPE $E_{t}^{k}$, the latter denoting the (linearly detrended and demeaned) cross-sectional standard deviations of the investment innovations. 
Table 9: The Relationship Between Dispersion, Individual Volatility and the Dispersion of INDIVIDUAL VOLATILITY

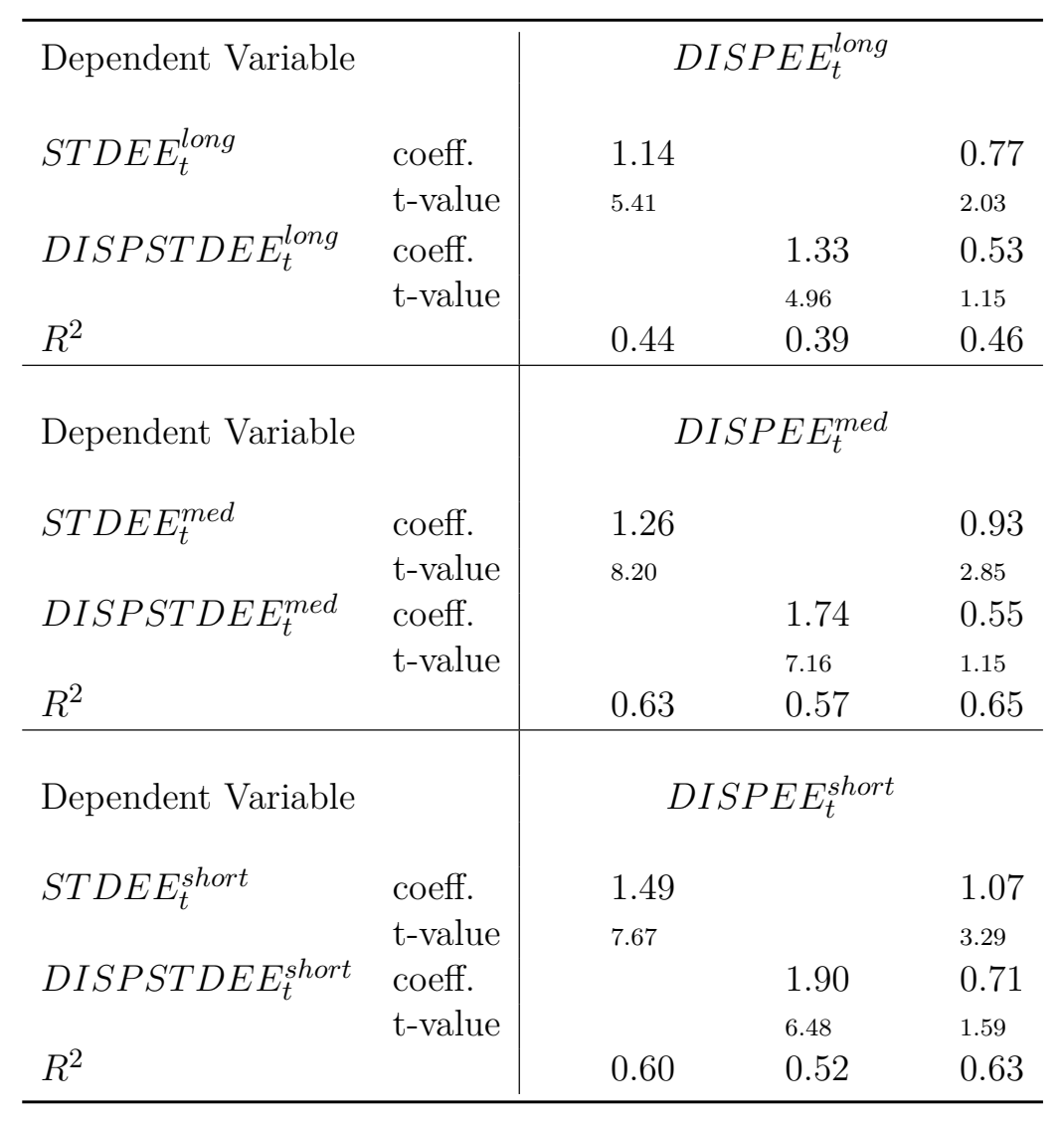

Notes: This table shows simple OLS regression output, coefficients, t-values and $R^{2}$, of regressions of $D I S P E E_{t}^{k}$ on $S T D E E_{t}^{k}$ and DISPSTDE $E_{t}^{k}$. All series are linearly detrended and demeaned.

\section{Conclusion}

This paper documents the empirical long-run and business cycle properties of a panel of firm-level investment surprises, derived from survey data on investment expectations and investment realizations in the West German manufacturing sector. Its novelty relative to the literature is that it uses quantitative expectations data to compute true investment innovations at the firm level. It thus provides direct quantitative discipline on the calibration of structural heterogeneous-firm models with idiosyncratic shocks and fixed capital investment. Recently popular models with firm-level risk shocks can use our results to calibrate the strength of these risk shocks. 


\section{References}

Arellano, C., Y. Bai, and P. J. Kehoe (2012): "Financial Frictions and Fluctuations in Volatility," Federal Reserve Bank of Minneapolis Research Department Staff Report 466.

Bachmann, R., and C. Bayer (2013a): "Investment Dispersion and the Business Cycle," American Economic Review, forthcoming.

(2013b): “Wait-and-See” Business Cycles?," Journal of Monetary Economics, 60(6), 704-719.

Bachmann, R., B. Born, S. Elstner, and C. Grimme (2013): "Time-varying Business Volatility, Price Setting, and the Real Effects of Monetary Policy," NBER Working Paper 19180.

Bachmann, R., and S. Elstner (2013): "Firms' Optimism and Pessimism," NBER Working Paper 18989.

Bachmann, R., S. Elstner, and E. R. Sims (2013): "Uncertainty and Economic Activity: Evidence from Business Survey Data," American Economic Journal: Macroeconomics, $5(2), 217-249$.

Bachmann, R., and G. Moscarini (2012): "Business Cycles and Endogenous Uncertainty," mimeo, Yale University.

Baker, S., And N. Bloom (2013): "Does Uncertainty Reduce Growth? Using Disasters as Natural Experiments," NBER Working Paper 19475.

Barro, R., E. Nakamura, J. Steinsson, and J. Ursua (2013): "Crises and Recoveries in an Empirical Model of Consumption Disasters," American Economic Journal: Macroeconomics, 5(3), 35-74.

Bellemare, C., and C. F. Manski (2011): "Special Issue: Measurement and Analysis of Subjective Expectations," in Journal of Applied Econometrics, pp. 351-547. Wiley.

Berger, D., and J. Vavra (2011): "Dynamics of the U.S. Price Distribution," mimeo.

Bloom, N. (2009): "The impact of uncertainty shocks," Econometrica, 77(3), 623-686.

Bloom, N., M. Floetotto, N. Jaimovich, I. Saporta-Eksten, and S. J. Terry (2012): "Really Uncertain Business Cycles," NBER Working Papers 18245. 
Bontempi, M., R. Golinelli, and G. Parigi (2010): "Why demand uncertainty curbs investment: Evidence from a panel of Italian manufacturing firms," Journal of Macroeconomics, 32(1), 218-238.

Christiano, L., R. Motto, and M. Rostagno (2014): "Risk Shocks," American Economic Review, 104(1), 27-65.

Chugh, S. (2012): "Firm Risk and Leverage-Based Business Cycles," mimeo, Boston College.

Comin, D., And S. Mulani (2006): "Diverging Trends in Aggregate and Firm Volatility," The Review of Economics and Statistics, 88(2), 374-383.

Cooper, R. W., and J. C. Haltiwanger (2006): "On the Nature of Capital Adjustment Costs," Review of Economic Studies, 73(3), 611-633.

Dave, C. (2011): "Are Investment Expectations Rational, Adaptive or Regressive?," Economic Inquiry, 49(1), 212-225.

Davis, S. J., J. C. Haltiwanger, R. Jarmin, and J. Miranda (2006): "Volatility and Dispersion in Business Growth Rates: Publicly Traded and Privately Held Firms," NBER Macroeconomics Annual.

De Leeuw, F., And M. J. McKelvey (1981): "Price expectations of business firms," Brookings Papers on Economic Activity, 1981(1), 299-314.

- (1984): "Price Expectations of Business Firms: Bias in the Short and Long Run," American Economic Review, 74(1), 99-110.

Döpke, J., M. Funke, S. Holly, and S. Weber (2005): "The cross-sectional dynamics of German business cycles: a bird's eye view," Discussion Paper Series 1: Economic Studies, 23.

DöPKe, J., AND S. Weber (2006): "The within-distribution business cycle dynamics of German firms," Discussion Paper Series 1: Economic Studies, 29.

Gilchrist, S., J. Sim, and E. ZakrajSeK (2010): "Uncertainty, Financial Frictions and Investment Dynamics," mimeo.

Gourio, F. (2008): "Estimating firm-level risk," mimeo, Boston University. (2013): "Disaster Risk and Business Cycles," American Economic Review, 102(6), $2734-66$. 
Guiso, L., And G. PARigi (1999): "Investment and Demand Uncertainty," The Quarterly Journal of Economics, 114(1), 185-227.

Guvenen, F., S. Ozkan, And J. Song (2012): "The Nature of Countercyclical Income Risk," NBER Working Paper 18035.

Higson, C., S. Holly, and P. Kattuman (2002): "The cross-sectional dynamics of the US business cycle: 1950-1999," Journal of Economic Dynamics and Control, 26(9/10), 1539-1555.

Higson, C., S. Holly, P. Kattuman, and S. Platis (2004): "The Business Cycle, Macroeconomic Shocks and the Cross-Section: The Growth of UK Quoted Companies," Economica, 71(282), 299-318.

Kenrig, M. (2012): "The cyclicality of productivity dispersion," mimeo, University of Texas - Austin.

Kehrig, M., And N. Vincent (2013): "Financial Frictions and Investment Dynamics in Multi-Plant Firms," mimeo, University of Texas - Austin.

Khan, A., And J. K. Thomas (2008): "Idiosyncratic shocks and the role of nonconvexities in plant and aggregate investment dynamics," Econometrica, 76(2), 395-436.

Midrigan, V. (2011): "Menu Costs, Multiproduct Firms, and Aggregate Fluctuations," Econometrica, 79(4), 1139-1180.

MülleR, H. C. (2011): "Forecast Errors in Undisclosed Management Sales Forecasts: The Disappearance of the Overoptimism Bias," DICE Discussion Paper No 40.

Müller, C., And E. M. KÖBerl (2007): "The Speed of Adjustment to Demand Shocks: A Markov-chain Measurement Using Micro Panel Data," KOF Working Papers, 170.

SACHVERStÄNDIGEnRAT (2009): "Die Zukunft nicht aufs Spiel setzen - Jahresgutachten $2009 / 10, "$.

VAvRA, J. (2014): "Inflation Dynamics and Time-Varying Uncertainty: New Evidence and an Ss Interpretation," The Quarterly Journal of Economics, 129(1), 215-258. 


\section{A Robustness Analysis - Two Samples with Fall Ob- servations Only}

In this appendix we present the results from the main text under two alternative sample definitions. We now define Realization ${ }_{i, t}=$ Realization fall $_{i, t}$ and include all firm-year observations regardless of consistency between the spring and the fall data. The two alternatives are: (i) we leave the outlier adjustment used to construct the baseline sample in place and eliminate firm-year observations that are smaller than the 1st percentile and larger than the 99th percentile for the corresponding year ('Outlier Adjusted'); (ii) we have no outlier adjustment ('Whole Sample').

Table 10: Summary Statistics - Pooled Cross-Section Of Investment InnovaTIONS, Fall Observations Only

\begin{tabular}{l|ccc|ccc}
\hline & \multicolumn{3}{|c|}{ Whole Sample } & \multicolumn{3}{c}{ Outlier Adjusted } \\
& $E E_{i, t}^{\text {long }}$ & $E E_{i, t}^{\text {med }}$ & $E E_{i, t}^{\text {short }}$ & $E E_{i, t}^{\text {long }}$ & $E E_{i, t}^{\text {med }}$ & $E E_{i, t}^{\text {short }}$ \\
\hline Statistics & & & & & & \\
Obs & 69,127 & 72,898 & 80,915 & 67,704 & 71,405 & 79,238 \\
Mean & 0.087 & -0.009 & 0.032 & 0.054 & 0.007 & 0.021 \\
Std.Dev. & 0.907 & 0.754 & 0.603 & 0.774 & 0.634 & 0.471 \\
Skewness & 0.085 & -0.019 & 0.009 & 0.012 & -0.106 & -0.006 \\
Kurtosis & 7.759 & 9.149 & 15.699 & 4.124 & 4.555 & 5.596 \\
& & & & & & \\
Percentiles & & & & & & \\
5th & -1.379 & -1.184 & -0.862 & -1.259 & -1.090 & -0.771 \\
10th & -0.916 & -0.783 & -0.526 & -0.873 & -0.740 & -0.501 \\
25th & -0.371 & -0.317 & -0.182 & -0.357 & -0.308 & -0.178 \\
50th & 0.031 & 0.000 & 0.000 & 0.031 & 0.000 & 0.000 \\
75th & 0.485 & 0.347 & 0.229 & 0.473 & 0.336 & 0.223 \\
90th & 1.037 & 0.787 & 0.579 & 0.985 & 0.745 & 0.543 \\
95th & 1.481 & 1.158 & 0.916 & 1.378 & 1.060 & 0.815 \\
& & & & & & \\
Mean of Abs $\left(E E_{i, t}^{k}\right)$ & 0.627 & 0.506 & 0.363 & 0.524 & 0.457 & 0.317 \\
& & & & & & \\
p-values of & & & & & & \\
Jarque-Bera Test & 0.00 & 0.00 & 0.00 & 0.00 & 0.00 & 0.00 \\
Kolmogoroff-Smirnov Test & 0.00 & 0.00 & 0.00 & 0.00 & 0.00 & 0.00 \\
\hline
\end{tabular}

Notes: The table provides a summary of the pooled (across firm-years) distributions of $E E_{i, t}^{l o n g}, E E_{i, t}^{m e d}$ and $E E_{i, t}^{\text {short }}$, when we define Realization ${ }_{i, t}=$ Realization $_{i, t}^{\text {fall }}$ and include all firm-year observations regardless of consistency between the spring and the fall data. The two alternatives are: (i) we eliminate firm-year observations smaller than the 1st percentile and larger than the 99th percentile for the corresponding year ('Outlier Adjusted'); (ii) we have no outlier adjustment ('Whole Sample'). The row 'Mean of $A b s\left(E E_{i, t}^{k}\right)$ ' displays the mean of the absolute values of $E E_{i, t}^{k}$. The last two rows show formal test results about the normality of the samples of investment innovations. 
Table 11: Cross-sectional Mean of Investment Innovations and the Business Cycle, Fall Observations Only

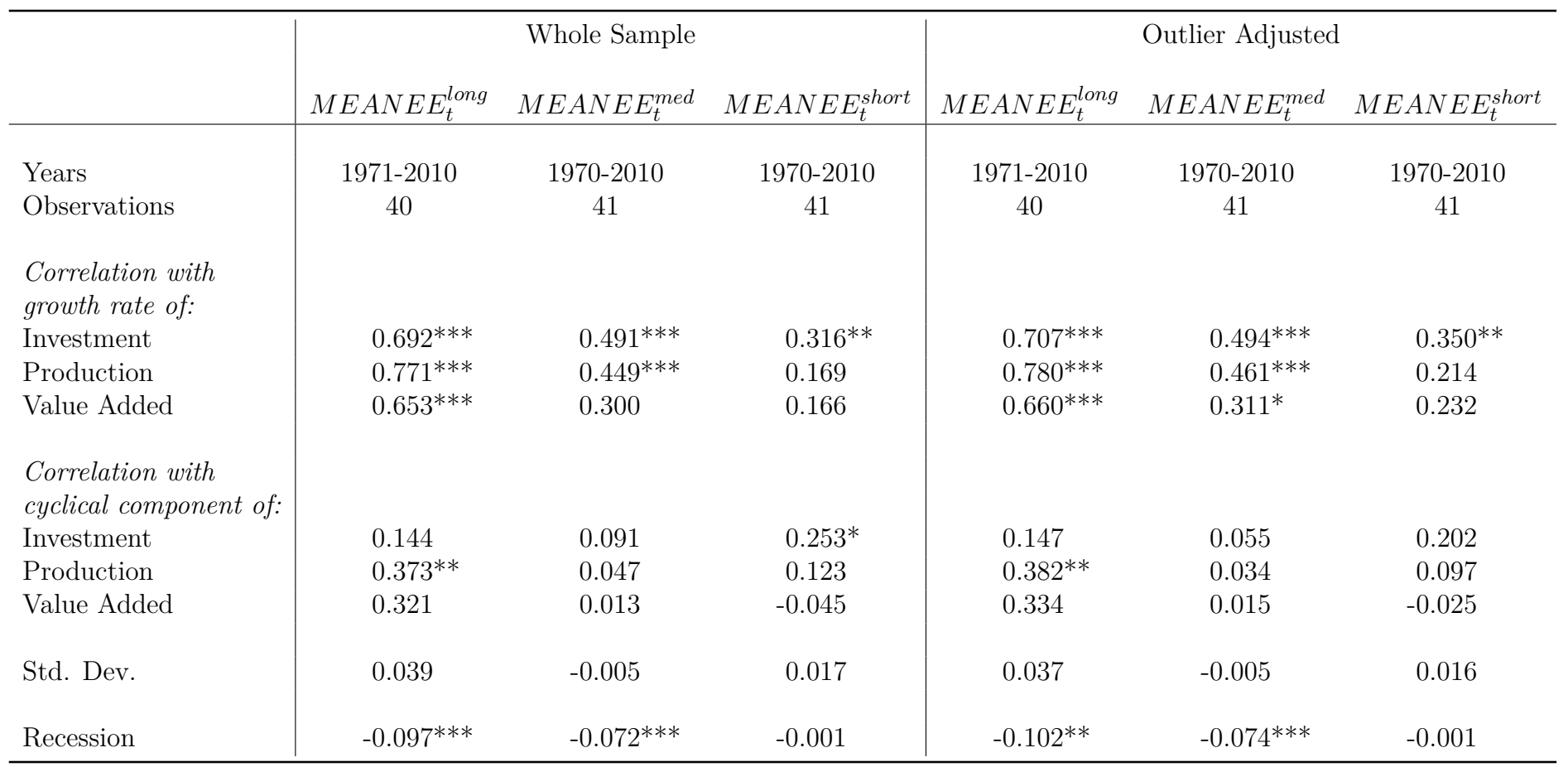

Notes: This table provides correlation coefficients between $M E A N E E_{t}^{k}$ and cyclical aggregate activity variables for the German manufacturing sector. This is the case where we define Realization $i, t=$ Realization $_{i, t}^{\text {fall }}$ and include all firm-year observations regardless of consistency between the spring and the fall data. The two alternatives are: (i) we eliminate firm-year observations smaller than the 1st percentile and larger than the 99th percentile for the corresponding year ('Outlier Adjusted'); (ii) we have no outlier adjustment ('Whole Sample'). We use as activity variables the (linearly detrended and demeaned) growth rates, computed as differences in the natural logarithm, and the HP(100)-filtered log time series, of, respectively, West German nominal investment expenditures in manufacturing and mining, an index of manufacturing real production, and an index of manufacturing real value added. Data for the activity variables are from the German Federal Statistical Office. All time series based on expectation errors are linearly detrended and demeaned. To test for significance of the time-series correlations (in a one-sided test) we use a nonparametric overlapping block bootstrap with a four-year window and with 10,000 replications. *** denotes $1 \%$ significance, $* * 5 \%$ significance and $* 10 \%$ significance. The penultimate row displays the time-series standard deviation of the linearly detrended and demeaned $M E A N E E_{t}^{k}$. The last row reports a regression estimate of the $M E A N E E_{t}^{k}$ on a constant and a recession indicator. For the latter, we use the definition proposed by Bloom et al. (2012) and take the share of quarters in that year that were defined as a recession. We use the recession dates provided by the Sachverständigenrat (see Sachverständigenrat, 2009, p. 261): II/1973 - II/1975, IV/1979 - IV/1982, I/1991 - III/1993, I/2001 - II/2005 and I/2008 - II/2009. To test the statistical significance of the recession coefficient we use Newey-West standard errors to account for any potential serial correlation. 
Table 12: Cross-Sectional Dispersion of Investment Innovations and the Business Cycle, Fall Observations Only

\begin{tabular}{|c|c|c|c|c|c|c|}
\hline & \multicolumn{3}{|c|}{ Whole Sample } & \multicolumn{3}{|c|}{ Outlier Adjusted } \\
\hline & $D I S P E E_{t}^{\text {long }}$ & DISPEE $E_{t}^{\text {med }}$ & $D I S P E E_{t}^{\text {short }}$ & $D I S P E E_{t}^{\text {long }}$ & $D I S P E E_{t}^{\text {med }}$ & DISPEE $E_{t}^{\text {short }}$ \\
\hline Years & $1971-2010$ & $1970-2010$ & $1970-2010$ & $1971-2010$ & $1970-2010$ & $1970-2010$ \\
\hline Observations & 40 & 41 & 41 & 40 & 41 & 41 \\
\hline $\begin{array}{l}\text { Correlation with } \\
\text { growth rate of: }\end{array}$ & & & & & & \\
\hline Investment, Std. Dev. $=0.092$ & $-0.581^{* * *}$ & $-0.216^{*}$ & -0.179 & $-0.599^{* * *}$ & $-0.275^{* *}$ & $-0.276^{*}$ \\
\hline Production, Std. Dev. $=0.050$ & $-0.397^{*}$ & -0.161 & -0.214 & $-0.388^{* *}$ & -0.176 & -0.197 \\
\hline Value Added, Std. Dev. $=0.049$ & $-0.279^{* *}$ & -0.105 & -0.077 & -0.364 & -0.101 & -0.045 \\
\hline $\begin{array}{l}\text { Correlation with } \\
\text { cyclical component of: }\end{array}$ & & & & & & \\
\hline Investment, Std. Dev. $=0.100$ & $-0.359^{* *}$ & -0.003 & -0.122 & $-0.431^{* * *}$ & -0.120 & -0.277 \\
\hline Production, Std. Dev. $=0.046$ & $-0.506^{* *}$ & -0.084 & -0.208 & $-0.559 * * *$ & -0.195 & -0.288 \\
\hline Value Added, Std. Dev. $=0.039$ & $-0.587 * * *$ & -0.264 & -0.325 & $-0.581^{* *}$ & -0.333 & -0.311 \\
\hline Recession & 0.029 & $0.044^{*}$ & $0.031^{*}$ & $0.025^{*}$ & 0.034 & $0.024^{*}$ \\
\hline Mean of raw DISPEE $E_{t}^{k}$ & 0.907 & 0.753 & 0.604 & 0.769 & 0.631 & 0.472 \\
\hline Coeff. of Variation & 0.058 & 0.079 & 0.070 & 0.060 & 0.079 & 0.071 \\
\hline
\end{tabular}

Notes: See notes to Table 11. The explanations there hold exactly here as well, replacing $M E A N E E_{t}^{k}$ with $D I S P E E_{t}^{k}$. The last two rows report the mean of the time-series average of the raw DISPE $E_{t}^{k}$, and the time-series coefficient of variation of DISPEE $E_{t}^{k}$, defined as the ratio of the time-series standard deviation of the (detrended and demeaned) series to the time-series average of the raw series. Cross-sectional dispersion is operationalized with the cross-sectional standard deviation in this table. The numbers in the first column after the designation of the cyclical indicators display their time-series standard deviation. 
Table 13: Cross-sectional Skewness of Investment Innovations and the Business Cycle, Fall Observations Only

\begin{tabular}{|c|c|c|c|c|c|c|}
\hline & \multicolumn{3}{|c|}{ Whole Sample } & \multicolumn{3}{|c|}{ Outlier Adjusted } \\
\hline & $S K E W E E_{t}^{l o n g}$ & $S K E W E E_{t}^{\text {med }}$ & $S K E W E E_{t}^{\text {short }}$ & $S K E W E E_{t}^{l o n g}$ & $S K E W E E_{t}^{m e d}$ & $S K E W E E_{t}^{\text {short }}$ \\
\hline Years & $1971-2010$ & $1970-2010$ & $1970-2010$ & $1971-2010$ & $1970-2010$ & $1970-2010$ \\
\hline Observations & 40 & 41 & 41 & 40 & 41 & 41 \\
\hline $\begin{array}{l}\text { Correlation with } \\
\text { growth rate of: }\end{array}$ & & & & & & \\
\hline Investment & -0.146 & -0.065 & -0.120 & 0.113 & -0.135 & 0.057 \\
\hline Production & 0.059 & -0.136 & -0.006 & $0.390 * *$ & -0.008 & $0.139^{* *}$ \\
\hline Value Added & 0.067 & -0.019 & -0.101 & $0.333^{*}$ & -0.041 & 0.025 \\
\hline $\begin{array}{l}\text { Correlation with } \\
\text { cyclical component of: }\end{array}$ & & & & & & \\
\hline Investment & -0.053 & $0.319^{* *}$ & 0.121 & $-0.140^{*}$ & -0.161 & -0.016 \\
\hline Production & -0.110 & 0.106 & -0.032 & 0.005 & $-0.299^{*}$ & -0.037 \\
\hline Value Added & -0.200 & 0.081 & -0.276 & -0.059 & $-0.300^{*}$ & $-0.235^{* *}$ \\
\hline Recession & -0.207 & 0.058 & -0.303 & -0.107 & -0.107 & $-0.098^{*}$ \\
\hline Mean of raw $S K E W E E_{t}^{k}$ & 0.131 & -0.007 & -0.009 & 0.078 & -0.063 & 0.011 \\
\hline Coeff. of Variation & 2.648 & 70.918 & 81.315 & 2.240 & 3.036 & 19.477 \\
\hline
\end{tabular}

Notes: See notes to Tables 11 and 12 . The explanations there hold exactly here as well, replacing $M E A N E E_{t}^{k} / D I S P E E_{t}^{k}$ with $S K E W E E_{t}^{k}$. 
Table 14: Cross-sectional Kurtosis of Investment Innovations and the Business Cycle, Fall Observations Only

\begin{tabular}{|c|c|c|c|c|c|c|}
\hline & \multicolumn{3}{|c|}{ Whole Sample } & \multicolumn{3}{|c|}{ Outlier Adjusted } \\
\hline & $K U R T E E_{t}^{l o n g}$ & $K U R T E E_{t}^{m e d}$ & $K U R T E E_{t}^{\text {short }}$ & $K U R T E E_{t}^{\text {long }}$ & $K U R T E E_{t}^{\text {med }}$ & $K U R T E E_{t}^{\text {short }}$ \\
\hline Years & $1971-2010$ & $1970-2010$ & $1970-2010$ & $1971-2010$ & $1970-2010$ & $1970-2010$ \\
\hline Observations & 40 & 41 & 41 & 40 & 41 & 41 \\
\hline $\begin{array}{l}\text { Correlation with } \\
\text { growth rate of: }\end{array}$ & & & & & & \\
\hline Investment & 0.065 & 0.214 & $0.359^{*}$ & 0.210 & 0.377 & $0.288^{*}$ \\
\hline Production & -0.024 & -0.071 & 0.021 & $0.375^{* * *}$ & $0.329^{* *}$ & $0.282^{* *}$ \\
\hline Value Added & -0.033 & 0.087 & -0.016 & $0.229 * * *$ & $0.273^{*}$ & $0.266^{* *}$ \\
\hline $\begin{array}{l}\text { Correlation with } \\
\text { cyclical component of: }\end{array}$ & & & & & & \\
\hline Investment & $0.351^{*}$ & $0.480^{* *}$ & $0.427^{* *}$ & 0.185 & 0.281 & $0.422^{* * *}$ \\
\hline Production & $0.203^{*}$ & $0.371^{* * *}$ & 0.256 & $0.457^{* *}$ & $0.565^{* * *}$ & $0.405^{* * *}$ \\
\hline Value Added & 0.033 & $0.356^{* *}$ & 0.118 & 0.268 & 0.424 & 0.112 \\
\hline Recession & -0.096 & 0.283 & 0.912 & -0.048 & -0.003 & -0.053 \\
\hline Mean of raw $K U R T E E_{t}^{k}$ & 7.684 & 8.930 & 15.300 & 4.080 & 4.385 & 5.478 \\
\hline Coeff. of Variation & 0.195 & 0.395 & 0.321 & 0.042 & 0.075 & 0.079 \\
\hline
\end{tabular}

Notes: See notes to Tables 11 and 12 . The explanations there hold exactly here as well, replacing $M E A N E E_{t}^{k} / D I S P E E_{t}^{k}$ with $K U R T E E_{t}^{k}$. 
Table 15: Cross-sectional Mean of the Individual Volatility of Investment Innovations and the Business CYCLE, Fall Observations Only

\begin{tabular}{|c|c|c|c|c|c|c|}
\hline & \multicolumn{3}{|c|}{ Whole Sample } & \multicolumn{3}{|c|}{ Outlier Adjusted } \\
\hline & $S T D E E_{t}^{\text {long }}$ & $S T D E E_{t}^{\text {med }}$ & $S T D E E_{t}^{\text {short }}$ & $S T D E E_{t}^{\text {long }}$ & $S T D E E_{t}^{\text {med }}$ & $S T D E E_{t}^{\text {short }}$ \\
\hline Years & $1972-2009$ & 1971-2009 & 1971-2009 & 1972-2009 & 1971-2009 & 1971-2009 \\
\hline Observations & 38 & 39 & 39 & 38 & 39 & 39 \\
\hline \multicolumn{7}{|l|}{$\begin{array}{l}\text { Correlation with } \\
\text { growth rate of: }\end{array}$} \\
\hline Investment, Std. Dev. $=0.092$ & $-0.418^{* *}$ & $-0.296^{*}$ & -0.225 & $-0.456^{* * *}$ & $-0.285^{*}$ & $-0.256^{*}$ \\
\hline Production, Std. Dev. $=0.050$ & -0.272 & -0.100 & -0.178 & -0.336 & -0.097 & -0.204 \\
\hline Value Added, Std. Dev. $=0.049$ & -0.312 & -0.086 & -0.101 & $-0.349^{*}$ & -0.079 & -0.098 \\
\hline \multicolumn{7}{|l|}{$\begin{array}{l}\text { Correlation with } \\
\text { cyclical component of: }\end{array}$} \\
\hline Investment, Std. Dev. $=0.100$ & -0.168 & -0.055 & -0.163 & -0.210 & -0.124 & -0.277 \\
\hline Production, Std. Dev. $=0.046$ & $-0.360^{* *}$ & -0.137 & -0.203 & $-0.368^{* *}$ & -0.177 & -0.266 \\
\hline Value Added, Std. Dev. $=0.039$ & $-0.472^{* * *}$ & $-0.279^{*}$ & $-0.261^{*}$ & $-0.480^{* *}$ & $-0.288^{*}$ & -0.225 \\
\hline Recession & $0.027^{* * *}$ & $0.045^{* *}$ & $0.025^{* * *}$ & $0.029^{* * *}$ & $0.039^{* *}$ & $0.021^{* * *}$ \\
\hline \multicolumn{7}{|l|}{$\begin{array}{l}\text { Correlation with } \\
\text { cross-sectional dispersion: }\end{array}$} \\
\hline$D I S P E E_{t}^{\text {long }}$ & $0.689^{* * *}$ & & & $0.683^{* * *}$ & & \\
\hline$D I S P E E_{t}^{\text {med }}$ & & $0.824^{* * *}$ & & & $0.832^{* * *}$ & \\
\hline$D I S P E E_{t}^{\text {short }}$ & & & $0.757^{* * *}$ & & & $0.793^{* * *}$ \\
\hline Mean of raw $S T D E E_{t}^{k}$ & 0.515 & 0.423 & 0.331 & 0.466 & 0.381 & 0.283 \\
\hline Coeff. of Variation & 0.048 & 0.091 & 0.059 & 0.050 & 0.085 & 0.056 \\
\hline
\end{tabular}

Notes: See notes to Tables 11 and 12. The explanations there hold exactly here as well, replacing $M E A N E E_{t}^{k} / D I S P E E_{t}^{k}$ with $S T D E E_{t}^{k}$. The panel 'Correlation with cross-sectional dispersion' shows the pairwise correlation coefficients between $S T D E E_{t}^{k}$ and DISPEE the (linearly detrended and demeaned) cross-sectional standard deviations of the investment innovations. 
Table 16: Cross-Sectional Standard Deviation of the Individual Volatility of Investment Innovations and The Business CyCle, Fall Observations Only

\begin{tabular}{|c|c|c|c|c|c|c|}
\hline & \multicolumn{3}{|c|}{ Whole Sample } & \multicolumn{3}{|c|}{ Outlier Adjusted } \\
\hline & $D I S P S T D E E_{t}^{\text {long }}$ & $D I S P S T D E E_{t}^{\text {med }}$ & DISPSTDEE $E_{t}^{\text {short }}$ & DISPSTDEE $E_{t}^{\text {long }}$ & $D I S P S T D E E_{t}^{\text {med }}$ & DISPSTDE E $E_{t}^{\text {short }}$ \\
\hline Years & 1972-2009 & 1971-2009 & 1971-2009 & 1972-2009 & 1971-2009 & 1971-2009 \\
\hline Observations & 38 & 39 & 39 & 38 & 39 & 39 \\
\hline \multicolumn{7}{|l|}{$\begin{array}{l}\text { Correlation with } \\
\text { growth rate of: }\end{array}$} \\
\hline Investment, Std. Dev. $=0.092$ & $-0.252^{* *}$ & -0.221 & 0.016 & $-0.469^{* * *}$ & -0.083 & -0.189 \\
\hline Production, Std. Dev. $=0.050$ & -0.022 & -0.075 & -0.049 & -0.256 & 0.005 & -0.106 \\
\hline Value Added, Std. Dev. $=0.049$ & -0.133 & -0.059 & -0.036 & -0.311 & 0.026 & -0.036 \\
\hline \multicolumn{7}{|l|}{$\begin{array}{l}\text { Correlation with } \\
\text { cyclical component of: }\end{array}$} \\
\hline Investment, Std. Dev. $=0.100$ & -0.072 & 0.090 & 0.210 & -0.211 & -0.092 & -0.066 \\
\hline Production, Std. Dev. $=0.046$ & -0.218 & -0.024 & 0.045 & -0.311 & -0.088 & -0.091 \\
\hline Value Added, Std. Dev. $=0.039$ & $-0.445^{* * *}$ & -0.245 & -0.180 & $-0.478^{* *}$ & -0.205 & -0.209 \\
\hline Recession & 0.015 & $0.036^{* *}$ & $0.030^{* *}$ & $0.019^{* * *}$ & $0.023^{*}$ & $0.016^{* *}$ \\
\hline \multicolumn{7}{|l|}{$\begin{array}{l}\text { Correlation with } \\
\text { cross-sectional dispersion: }\end{array}$} \\
\hline$D I S P E E_{t}^{\text {long }}$ & $0.526^{* * *}$ & & & $0.653^{* * *}$ & & \\
\hline$D I S P E E_{t}^{\text {med }}$ & & $0.829^{* * *}$ & & & $0.826^{* * *}$ & \\
\hline DISPEE $E_{t}^{\text {short }}$ & & & $0.746^{* * *}$ & & & $0.732^{* * *}$ \\
\hline Mean of raw DISPSTDE $E_{t}^{k}$ & 0.415 & 0.353 & 0.325 & 0.327 & 0.275 & 0.223 \\
\hline Coeff. of Variation & 0.059 & 0.099 & 0.084 & 0.051 & 0.088 & 0.068 \\
\hline
\end{tabular}

Notes: See notes to Tables 11 and 12. The explanations there hold exactly here as well, replacing MEANEE $E_{t}^{k} / D I S P E E_{t}^{k}$ with DISPSTDEE $E_{t}^{k}$. The panel 'Correlation with cross-sectional dispersion' shows the pairwise correlation coefficients between DISPSTDE $E_{t}^{k}$ and DISPEE $E_{t}^{k}$, the latter denoting the (linearly detrended and demeaned) cross-sectional standard deviations of the investment innovations. 


\section{B Robustness Analysis - Weighting the Baseline Sam- ple}

One possible concern with the results in the main body of the paper, which are obtained by using the industry representation as given in the IFO-IS, is that they might suffer from an unrepresentative industry composition, when compared to the aggregate. To check whether our results are driven by the IFO-IS industry representation, we compute three different robustness checks to our baseline, unweighted results. Specifically, we assign each firm-year observation a weight such that the corresponding two-digit industry within the IFO-IS sample has the same total weight as (i) the fraction of firms in this industry in the manufacturing (plus mining) aggregate (the leftmost panel in the following tables), (ii) the fraction of plants in this industry in the manufacturing (plus mining) aggregate (the center panel in the following tables), and (iii) the fraction of investment in this industry in the manufacturing (plus mining) aggregate (the rightmost panel in the following tables). In all three cases, the two-digit industries are defined according to the German WZ 2003 industry classification. The data on the number of firms and plants and the amount of investment within each two-digit industry comes from the Federal Statistical Agency.

We have data on the industry firm distribution from 1995 to 2008 and use it to compute the fraction of firms within each industry for every year in the sample. The weights we use to reweight the IFO-IS results to are simply the time-series averages of these weights. They can be seen in the leftmost panel of Table 17. Similarly, we have data on the industry plant distribution from 1991 to 2008 and use it to compute the fraction of plants within each industry for every year in the sample. The weights we use to reweight the IFO-IS results to are again the time-series averages of these weights. They can be seen in the center panel of Table 17. Finally, we have data on investment by industry from 1970 to 2008, i.e., a longer time series of investment weights. We use ten-year moving averages of these weights, extrapolating the beginning and the end of the weights series, to reweight the IFO-IS results.

For the sake of readability, we report the time-series average of these moving average weights in Table 17, in the rightmost panel. 


\section{Table 17: Two-Digit Industry Composition}

\begin{tabular}{l|ccc}
\hline \multicolumn{2}{l}{ Industry Classification: WZ 2003} & & \\
& & & \\
Two-digit Industry & Firm Shares & Plant Shares & Investment Shares \\
& & & \\
\hline Mining & $1.77 \%$ & $2.89 \%$ & $3.67 \%$ \\
Food and Tobacco & $13 \%$ & $11.89 \%$ & $9.90 \%$ \\
Textile Products & $4.04 \%$ & $4.46 \%$ & $2.39 \%$ \\
Leather & $0.58 \%$ & $0.65 \%$ & $0.25 \%$ \\
Wood & $4.04 \%$ & $4.01 \%$ & $1.50 \%$ \\
Paper and Printing & $8.74 \%$ & $7.99 \%$ & $8.09 \%$ \\
Oil & $0.12 \%$ & $0.16 \%$ & $2.11 \%$ \\
Chemical Industry & $3.37 \%$ & $3.69 \%$ & $11.72 \%$ \\
Plastics and Rubber & $6.71 \%$ & $6.27 \%$ & $3.85 \%$ \\
Glass and Ceramics & $5.13 \%$ & $7.33 \%$ & $4.45 \%$ \\
Metal Products & $17.86 \%$ & $16.54 \%$ & $12.03 \%$ \\
Machinery and Equipment & $15.04 \%$ & $14.59 \%$ & $9.52 \%$ \\
Electrical Equipment & $11.58 \%$ & $11.54 \%$ & $12.24 \%$ \\
Transport Equipment & $3.11 \%$ & $3.27 \%$ & $15.88 \%$ \\
Furniture and Jewelery & $4.92 \%$ & $4.71 \%$ & $2.40 \%$ \\
& & & \\
Manufacturing and Mining & $\mathbf{1 0 0 \%}$ & $\mathbf{1 0 0 \%}$ & $\mathbf{1 0 0 \%}$ \\
\hline
\end{tabular}

Notes: This table shows the two-digit industry composition in the manufacturing (plus mining) sector, according to the number of firms, the number of plants and investment within each two-digit industry. The data are from the Federal Statistical Agency. 
Table 18: Summary Statistics - Pooled Cross-Section of Investment Innovations, Weighted Samples

\begin{tabular}{|c|c|c|c|c|c|c|c|c|c|}
\hline \multirow[b]{2}{*}{ Statistics } & \multicolumn{3}{|c|}{$\begin{array}{l}\text { Weight: Percentage number } \\
\text { of firms per industry }\end{array}$} & \multicolumn{3}{|c|}{$\begin{array}{l}\text { Weight: Percentage number } \\
\text { of plants per industry }\end{array}$} & \multicolumn{3}{|c|}{$\begin{array}{c}\text { Weight: Moving average } \\
\text { of share of investment } \\
\text { per industry }\end{array}$} \\
\hline & $E E_{i, t}^{l o n g}$ & $E E_{i, t}^{\text {med }}$ & $E E_{i, t}^{s h o r t}$ & $E E_{i, t}^{l o n g}$ & $E E_{i, t}^{\text {med }}$ & $E E_{i, t}^{\text {short }}$ & $E E_{i, t}^{l o n g}$ & $E E_{i, t}^{\text {med }}$ & $E E_{i, t}^{\text {short }}$ \\
\hline Obs & 47,159 & 52,528 & 54,606 & 47,144 & 52,530 & 54,615 & 46,927 & 52,342 & 54,372 \\
\hline Mean & 0.034 & -0.011 & 0.009 & 0.034 & -0.012 & 0.009 & 0.034 & -0.012 & 0.009 \\
\hline Std.Dev. & 0.739 & 0.589 & 0.417 & 0.738 & 0.589 & 0.418 & 0.722 & 0.578 & 0.406 \\
\hline Skewness & 0.029 & -0.145 & -0.082 & 0.026 & -0.156 & -0.067 & 0.024 & -0.150 & -0.067 \\
\hline Kurtosis & 4.171 & 4.660 & 5.804 & 4.165 & 4.667 & 5.895 & 4.008 & 4.512 & 5.655 \\
\hline \multicolumn{10}{|l|}{ Percentiles } \\
\hline 5 th & -1.209 & -1.033 & -0.693 & -1.207 & -1.003 & -0.693 & -1.188 & -1.002 & -0.691 \\
\hline 10 th & -0.848 & -0.698 & -0.445 & -0.848 & -0.699 & -0.445 & -0.838 & -0.693 & -0.439 \\
\hline 25 th & -0.360 & -0.299 & -0.162 & -0.360 & -0.299 & -0.162 & -0.356 & -0.297 & -0.162 \\
\hline 50 th & -0.008 & 0.000 & 0.000 & -0.008 & 0.000 & 0.000 & -0.008 & 0.000 & 0.000 \\
\hline 75th & 0.431 & 0.289 & 0.184 & 0.431 & 0.289 & 0.184 & 0.428 & 0.287 & 0.182 \\
\hline 90th & 0.921 & 0.671 & 0.470 & 0.920 & 0.670 & 0.470 & 0.916 & 0.664 & 0.466 \\
\hline 95 th & 1.300 & 0.962 & 0.693 & 1.299 & 0.962 & 0.693 & 1.178 & 0.949 & 0.693 \\
\hline Mean of $A b s\left(E E_{i, t}^{k}\right)$ & 0.543 & 0.422 & 0.310 & 0.542 & 0.422 & 0.278 & 0.534 & 0.417 & 0.273 \\
\hline \multicolumn{10}{|l|}{ p-values of } \\
\hline Jarque-Bera Test & 0.00 & 0.00 & 0.00 & 0.00 & 0.00 & 0.00 & 0.00 & 0.00 & 0.00 \\
\hline Kolmogoroff-Smirnov Test & 0.00 & 0.00 & 0.00 & 0.00 & 0.00 & 0.00 & 0.00 & 0.00 & 0.00 \\
\hline
\end{tabular}

Notes: The table provides a summary of the pooled (across firm-years) distributions of $E E_{i, t}^{l o n g}, E E_{i, t}^{\text {med }}$ and $E E_{i, t}^{\text {short}}$, for the case of the weighted samples (see Table 17). The row 'Mean of $A b s\left(E E_{i, t}^{k}\right)$ ' displays the mean of the absolute values of $E E_{i, t}^{k}$. The last two rows show formal test results about the normality of the samples of investment innovations. 


\section{Table 19: Cross-sectional Mean of Investment Innovations and the Business Cycle, Weighted Samples}

\begin{tabular}{|c|c|c|c|c|c|c|c|c|c|}
\hline & \multicolumn{3}{|c|}{$\begin{array}{l}\text { Weight: Percentage number } \\
\text { of firms per industry }\end{array}$} & \multicolumn{3}{|c|}{$\begin{array}{l}\text { Weight: Percentage number } \\
\text { of plants per industry }\end{array}$} & \multicolumn{3}{|c|}{$\begin{array}{c}\text { Weight: Moving average } \\
\text { of share of investment } \\
\text { per industry }\end{array}$} \\
\hline & $M E A N E E_{t}^{\text {long }}$ & $M E A N E E_{t}^{\text {med }}$ & $M E A N E E_{t}^{\text {short }}$ & $M E A N E E_{t}^{\text {long }}$ & $M E A N E E_{t}^{\text {med }}$ & $M E A N E E_{t}^{\text {short }}$ & $M E A N E E_{t}^{\text {long }}$ & $M E A N E E_{t}^{\text {med }}$ & $M E A N E E_{t}^{\text {short }}$ \\
\hline $\begin{array}{l}\text { Years } \\
\text { Observations }\end{array}$ & $\begin{array}{l}1971-2010 \\
40\end{array}$ & $\begin{array}{c}1970-2010 \\
41\end{array}$ & $\begin{array}{c}1970-2010 \\
41\end{array}$ & $\begin{array}{l}1971-2010 \\
40\end{array}$ & $\begin{array}{c}1970-2010 \\
41\end{array}$ & $\begin{array}{c}1970-2010 \\
41\end{array}$ & $\begin{array}{l}1971-2010 \\
40\end{array}$ & $\begin{array}{c}1970-2010 \\
41\end{array}$ & $\begin{array}{c}1970-2010 \\
41\end{array}$ \\
\hline $\begin{array}{l}\text { Correlation with } \\
\text { growth rate of: } \\
\text { Investment } \\
\text { Production } \\
\text { Value Added }\end{array}$ & $\begin{array}{l}0.713^{* * *} \\
0.786^{* * *} \\
0.681^{* * *}\end{array}$ & $\begin{array}{l}0.540^{* * *} \\
0.474^{* * *} \\
0.375\end{array}$ & $\begin{array}{l}0.389^{* * *} \\
0.125 \\
0.233\end{array}$ & $\begin{array}{l}0.676^{* * *} \\
0.794^{* * *} \\
0.619^{* *}\end{array}$ & $\begin{array}{l}0.478^{* * *} \\
0.467^{* * *} \\
0.315\end{array}$ & $\begin{array}{l}0.349^{* *} \\
0.140 \\
0.148\end{array}$ & $\begin{array}{l}0.707^{* * *} \\
0.775^{* * *} \\
0.607^{*}\end{array}$ & $\begin{array}{l}0.419^{*} \\
0.537^{* * *} \\
0.437\end{array}$ & $\begin{array}{l}0.360^{* *} \\
0.207 \\
0.271\end{array}$ \\
\hline $\begin{array}{l}\text { Correlation with } \\
\text { cyclical component of: } \\
\text { Investment } \\
\text { Production } \\
\text { Value Added }\end{array}$ & $\begin{array}{l}0.203^{*} \\
0.442^{* *} \\
0.386\end{array}$ & $\begin{array}{l}0.142^{*} \\
0.137 \\
0.138\end{array}$ & $\begin{array}{l}0.308^{* *} \\
0.114 \\
0.026\end{array}$ & $\begin{array}{l}0.206^{* *} \\
0.445^{* * *} \\
0.386^{* *}\end{array}$ & $\begin{array}{l}0.133 \\
0.128 \\
0.137\end{array}$ & $\begin{array}{l}0.292^{* *} \\
0.109 \\
0.021\end{array}$ & $\begin{array}{l}0.236^{* * *} \\
0.459^{* * *} \\
0.430^{* *}\end{array}$ & $\begin{array}{l}0.073 \\
0.206 \\
0.242\end{array}$ & $\begin{array}{l}0.275^{*} \\
0.250^{*} \\
0.152\end{array}$ \\
\hline Std. Dev. & 0.133 & 0.077 & 0.030 & 0.131 & 0.076 & 0.030 & 0.129 & 0.068 & 0.031 \\
\hline Recession & $-0.132^{* * *}$ & $-0.055^{* * *}$ & -0.002 & $-0.130^{* * *}$ & $-0.055^{* * *}$ & -0.001 & $-0.125^{* * *}$ & $-0.047^{* * *}$ & 0.002 \\
\hline
\end{tabular}

Notes: This table provides correlation coefficients between $M E A N E E_{t}^{k}$ and cyclical aggregate activity variables for the German manufacturing sector, for the case of the weighted samples (see Table 17). We use as activity variables the (linearly detrended and demeaned) growth rates, computed as differences in the natural logarithm, and the HP(100)-filtered log time series, of, respectively, West German nominal investment expenditures in manufacturing and mining, an index of manufacturing real production, and an index of manufacturing real value added. Data for the activity variables are from the German Federal Statistical Office. All time series based on expectation errors are linearly detrended and demeaned. To test for significance of the time-series correlations (in a one-sided test) we use a nonparametric overlapping block bootstrap with a four-year window and with 10,000 replications. ${ }^{* * *}$ denotes $1 \%$ significance, ${ }^{* *} 5 \%$ significance and $* 10 \%$ significance. The penultimate row displays the time-series standard deviation of the linearly detrended and demeaned $M E A N E E_{t}^{k}$. The last row reports a regression estimate of the $M E A N E E_{t}^{k}$ on a constant and a recession indicator. For the latter, we use the definition proposed by Bloom et al. (2012) and take the share of quarters in that year that were defined as a recession. We use the recession dates provided by the Sachverständigenrat (see Sachverständigenrat, 2009, p. 261): II/1973 - II/1975, IV/1979 IV/1982, I/1991 - III/1993, I/2001 - II/2005 and I/2008 - II/2009. To test the statistical significance of the recession coefficient we use Newey-West standard errors to account for any potential serial correlation. 
Table 20: Cross-sectional Dispersion of Investment Innovations and the Business Cycle, Weighted Samples

\begin{tabular}{|c|c|c|c|c|c|c|c|c|c|}
\hline & \multicolumn{3}{|c|}{$\begin{array}{l}\text { Weight: Percentage number } \\
\text { of firms per industry }\end{array}$} & \multicolumn{3}{|c|}{$\begin{array}{l}\text { Weight: Percentage number } \\
\text { of plants per industry }\end{array}$} & \multicolumn{3}{|c|}{$\begin{array}{c}\text { Weight: Moving average } \\
\text { of share of investment } \\
\text { per industry }\end{array}$} \\
\hline & $D I S P E E_{t}^{l o n g}$ & $D I S P E E_{t}^{\text {med }}$ & DISPEE $E_{t}^{\text {short }}$ & $D I S P E E_{t}^{\text {long }}$ & $D I S P E E_{t}^{\text {med }}$ & DISPEE $E_{t}^{\text {short }}$ & DISPEE $E_{t}^{\text {long }}$ & $D I S P E E_{t}^{\text {med }}$ & DISPEE $E_{t}^{\text {short }}$ \\
\hline Years & $1971-2010$ & $1970-2010$ & $1970-2010$ & $1971-2010$ & $1970-2010$ & $1970-2010$ & 1971-2010 & $1970-2010$ & 1970-2010 \\
\hline Observations & 40 & 41 & 41 & 40 & 41 & 41 & 40 & 41 & 41 \\
\hline $\begin{array}{l}\text { Correlation with } \\
\text { growth rate of: }\end{array}$ & & & & & & & & & \\
\hline Investment, Std. Dev. $=0.092$ & $-0.484^{* * *}$ & $-0.293^{* * *}$ & $-0.236^{* * *}$ & $-0.477^{* * *}$ & $-0.289^{* * *}$ & $-0.218^{* * *}$ & $-0.420^{* *}$ & $-0.348^{* * *}$ & $-0.298^{* * *}$ \\
\hline Production, Std. Dev. $=0.050$ & $-0.305^{* *}$ & -0.075 & -0.022 & $-0.303^{* *}$ & -0.055 & -0.009 & -0.309 & -0.138 & -0.106 \\
\hline Value Added, Std. Dev. $=0.049$ & -0.154 & 0.010 & 0.121 & -0.161 & 0.022 & 0.131 & -0.197 & -0.064 & 0.038 \\
\hline $\begin{array}{l}\text { Correlation with } \\
\text { cyclical component of: }\end{array}$ & & & & & & & & & \\
\hline Investment, Std. Dev. $=0.100$ & $-0.351^{* *}$ & $-0.207^{*}$ & $-0.339^{* *}$ & $-0.341^{* *}$ & $-0.219^{*}$ & $-0.336^{* *}$ & $-0.302^{*}$ & $-0.222^{* *}$ & $-0.377^{* *}$ \\
\hline Production, Std. Dev. $=0.046$ & $-0.431^{* *}$ & -0.197 & $-0.225^{* *}$ & $-0.421^{*}$ & -0.184 & $-0.211^{*}$ & -0.384 & -0.186 & $-0.228^{* *}$ \\
\hline Value Added, Std. Dev. $=0.039$ & $-0.425^{*}$ & $-0.258^{*}$ & -0.077 & $-0.429^{*}$ & -0.257 & -0.067 & -0.403 & -0.270 & -0.063 \\
\hline Recession & 0.025 & 0.044 & $0.033^{*}$ & 0.026 & 0.045 & $0.035^{*}$ & 0.015 & 0.036 & 0.026 \\
\hline Mean of raw DISPEE $E_{t}^{k}$ & 0.715 & 0.574 & 0.410 & 0.714 & 0.573 & 0.411 & 0.665 & 0.538 & 0.382 \\
\hline Coeff. of Variation & 0.065 & 0.090 & 0.088 & 0.066 & 0.091 & 0.091 & 0.067 & 0.090 & 0.100 \\
\hline
\end{tabular}

Notes: See notes to Table 19. The explanations there hold exactly here as well, replacing $M E A N E E_{t}^{k}$ with $D I S P E E_{t}^{k}$. The last two rows report the mean of the time-series average of the raw DISPE $E_{t}^{k}$, and the time-series coefficient of variation of DISPEE $E_{t}^{k}$, defined as the ratio of the time-series standard deviation of the (detrended and demeaned) series to the time-series average of the raw series. Cross-sectional dispersion is operationalized with the cross-sectional standard deviation in this table. The numbers in the first column after the designation of the cyclical indicators display their time-series standard deviation. 
Table 21: Cross-Sectional Skewness of Investment Innovations and the Business Cycle, Weighted Samples

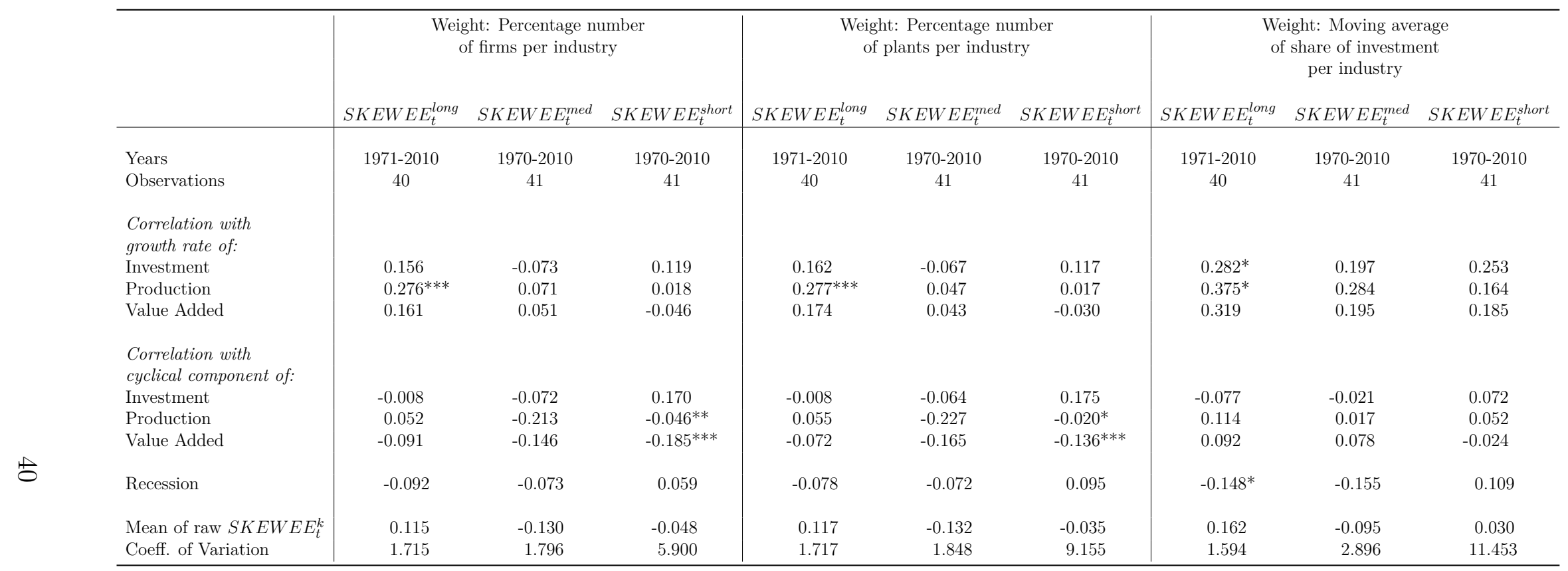

Notes: See notes to Tables 19 and 20. The explanations there hold exactly here as well, replacing $M E A N E E_{t}^{k} / D I S P E E_{t}^{k}$ with $S K E W E E_{t}^{k}$. 
Table 22: Cross-sectional Kurtosis of Investment Innovations and the Business Cycle, Weighted Samples

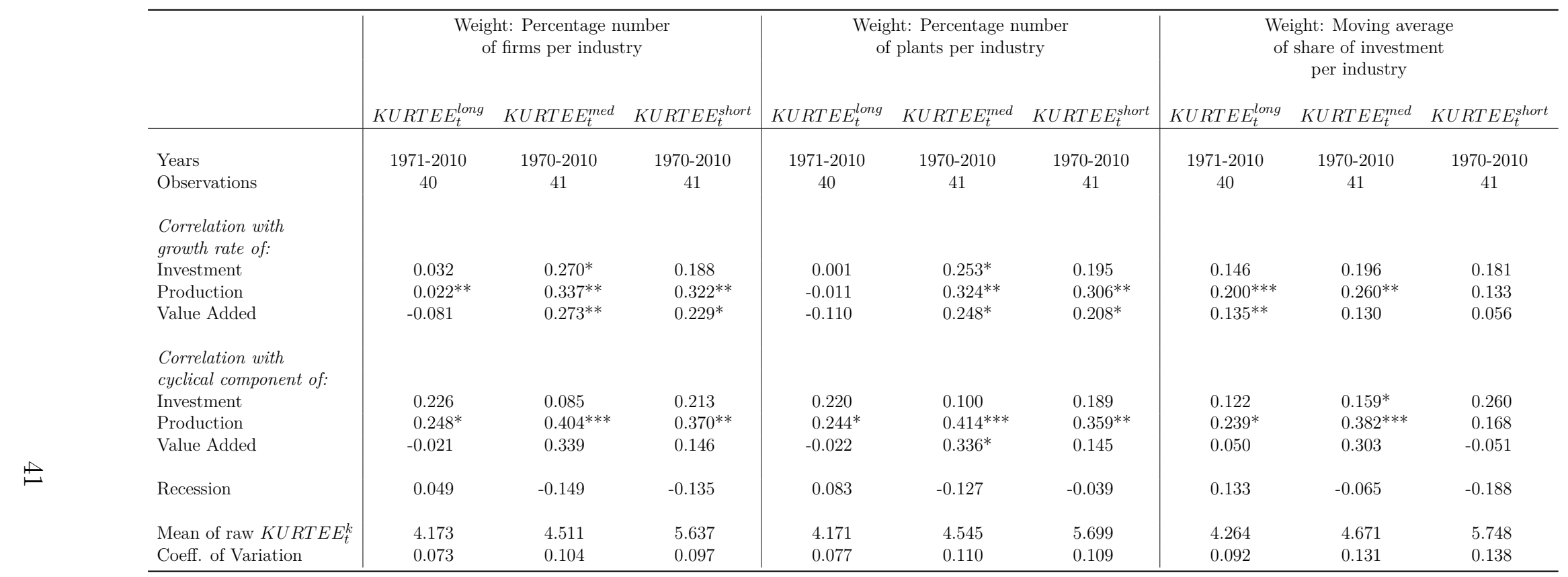

Notes: See notes to Tables 19 and 20. The explanations there hold exactly here as well, replacing $M E A N E E_{t}^{k} / D I S P E E_{t}^{k}$ with $K U R T E E_{t}^{k}$. 
Table 23: Cross-sectional Mean of the Individual Volatility of Investment Innovations and the Business CyCLE, Weighted Samples

\begin{tabular}{|c|c|c|c|c|c|c|c|c|c|}
\hline & \multicolumn{3}{|c|}{$\begin{array}{l}\text { Weight: Percentage number } \\
\text { of firms per industry }\end{array}$} & \multicolumn{3}{|c|}{$\begin{array}{l}\text { Weight: Percentage number } \\
\text { of plants per industry }\end{array}$} & \multicolumn{3}{|c|}{$\begin{array}{c}\text { Weight: Moving average } \\
\text { of share of investment } \\
\text { per industry }\end{array}$} \\
\hline & $S T D E E_{t}^{\text {long }}$ & $S T D E E_{t}^{\text {med }}$ & $S T D E E_{t}^{\text {short }}$ & $S T D E E_{t}^{\text {long }}$ & $S T D E E_{t}^{\text {med }}$ & $S T D E E_{t}^{\text {short }}$ & $S T D E E_{t}^{\text {long }}$ & $S T D E E_{t}^{\text {med }}$ & $S T D E E_{t}^{\text {short }}$ \\
\hline Years & 1972-2009 & 1971-2009 & 1971-2009 & 1972-2009 & 1971-2009 & 1971-2009 & 1972-2009 & 1971-2009 & 1971-2009 \\
\hline Observations & 38 & 39 & 39 & 38 & 39 & 39 & 38 & 39 & 39 \\
\hline \multicolumn{10}{|l|}{$\begin{array}{l}\text { Correlation with } \\
\text { growth rate of: }\end{array}$} \\
\hline Investment, Std. Dev. $=0.092$ & $-0.449^{* * *}$ & $-0.289^{* *}$ & $-0.261^{* * *}$ & $-0.442^{* * *}$ & $-0.295^{* *}$ & $-0.273^{* * *}$ & $-0.488^{* * *}$ & $-0.336^{* * *}$ & $-0.262^{* * *}$ \\
\hline Production, Std. Dev. $=0.050$ & $-0.418^{* * *}$ & -0.060 & $-0.200 * *$ & $-0.399 * * *$ & -0.051 & $-0.219 * *$ & $-0.383^{* * *}$ & -0.084 & $-0.161^{* *}$ \\
\hline Value Added, Std. Dev. $=0.049$ & $-0.419^{* * *}$ & -0.043 & $-0.143^{* *}$ & $-0.409^{* * *}$ & -0.046 & $-0.159^{* *}$ & $-0.426^{* * *}$ & -0.076 & $-0.133^{*}$ \\
\hline \multicolumn{10}{|l|}{$\begin{array}{l}\text { Correlation with } \\
\text { cyclical component of: }\end{array}$} \\
\hline Investment, Std. Dev. $=0.100$ & -0.209 & -0.173 & -0.334 & -0.218 & -0.181 & -0.324 & $-0.252^{* *}$ & -0.169 & -0.305 \\
\hline Production, Std. Dev. $=0.046$ & $-0.475^{* * *}$ & -0.196 & $-0.376^{* *}$ & $-0.466^{* * *}$ & -0.199 & $-0.379^{* *}$ & $-0.475^{* * *}$ & -0.200 & $-0.356^{* *}$ \\
\hline Value Added, Std. Dev. = 0.039 & $-0.465^{* * *}$ & $-0.255^{*}$ & -0.209 & $-0.469^{* * *}$ & $-0.275^{* *}$ & -0.222 & $-0.476^{* * *}$ & $-0.329^{* *}$ & $-0.184^{*}$ \\
\hline Recession & $0.030^{* * *}$ & $0.032^{*}$ & $0.019^{* *}$ & $0.030^{* * *}$ & $0.030^{*}$ & $0.019^{* *}$ & $0.024^{* *}$ & $0.025^{*}$ & 0.012 \\
\hline \multicolumn{10}{|l|}{$\begin{array}{l}\text { Correlation with } \\
\text { cross-sectional dispersion: }\end{array}$} \\
\hline$D I S P E E_{t}^{l o n g}$ & $0.569^{* * *}$ & & & $0.562^{* * *}$ & & & $0.390^{* * *}$ & & \\
\hline DISPEE E & & $0.770 * * *$ & & & $0.764^{* * *}$ & & & $0.617^{* * *}$ & \\
\hline DISPEE $E_{t}^{\text {short }}$ & & & $0.734^{* * *}$ & & & $0.738^{* * *}$ & & & $0.678^{* * *}$ \\
\hline Mean of raw $S T D E E_{t}^{k}$ & 0.408 & 0.340 & 0.228 & 0.407 & 0.339 & 0.228 & 0.377 & 0.316 & 0.210 \\
\hline Coeff. of Variation & 0.063 & 0.094 & 0.081 & 0.064 & 0.092 & 0.083 & 0.071 & 0.088 & 0.080 \\
\hline
\end{tabular}

Notes: See notes to Tables 19 and 20. The explanations there hold exactly here as well, replacing $M E A N E E_{t}^{k} / D I S P E E_{t}^{k}$ with $S T D E E_{t}^{k}$. The panel 'Correlation with cross-sectional dispersion' shows the pairwise correlation coefficients between $S T D E E_{t}^{k}$ and DISPEE $E_{t}^{k}$, the latter denoting the (linearly detrended and demeaned) cross-sectional standard deviations of the investment innovations. 
Table 24: Cross-Sectional Standard Deviation of the Individual Volatility of Investment Innovations and the Business Cycle, Weighted Samples

\begin{tabular}{|c|c|c|c|c|c|c|c|c|c|}
\hline & \multicolumn{3}{|c|}{$\begin{array}{l}\text { Weight: Percentage number } \\
\text { of firms per industry }\end{array}$} & \multicolumn{3}{|c|}{$\begin{array}{l}\text { Weight: Percentage number } \\
\text { of plants per industry }\end{array}$} & \multicolumn{3}{|c|}{$\begin{array}{l}\text { Weight: Moving average } \\
\text { of share of investment } \\
\text { per industry }\end{array}$} \\
\hline & DISPSTDE $E_{t}^{\text {long }}$ & DISPSTDE $E_{t}^{\text {med }}$ & DISPSTDEE Et short & DISPSTDEE $E_{t}^{\text {long }}$ & $D I S P S T D E E_{t}^{\text {med }}$ & DISPSTDEE $E_{t}^{\text {short }}$ & DISPSTDE $E_{t}^{\text {long }}$ & DISPSTDE $E_{t}^{\text {med }}$ & DISPSTDE $E_{t}^{\text {short }}$ \\
\hline $\begin{array}{l}\text { Years } \\
\text { Observations }\end{array}$ & $\begin{array}{c}1972-2010 \\
38\end{array}$ & $\begin{array}{c}1971-2009 \\
39\end{array}$ & $\begin{array}{c}1971-2009 \\
39\end{array}$ & $\begin{array}{c}1972-2009 \\
38\end{array}$ & $\begin{array}{c}1971-2009 \\
39\end{array}$ & $\begin{array}{c}1970-2009 \\
39\end{array}$ & $\begin{array}{c}1972-2009 \\
38\end{array}$ & $\begin{array}{c}1971-2009 \\
39\end{array}$ & $\begin{array}{c}1970-2009 \\
30\end{array}$ \\
\hline $\begin{array}{l}\text { Correlation with } \\
\text { growth rate of: } \\
\text { Investment, Std. Dev. }=0.092 \\
\text { Production, Std. Dev. }=0.050 \\
\text { Value Added, Std. Dev. }=0.046\end{array}$ & $\begin{array}{l}-0.343^{* *} \\
-0.268 \\
-0.275\end{array}$ & $\begin{array}{r}-0.132 \\
0.108 \\
0.095\end{array}$ & $\begin{array}{l}-0.184 \\
-0.115 \\
-0.102\end{array}$ & $\begin{array}{l}-0.328^{* *} \\
-0.252 \\
-0.252\end{array}$ & $\begin{array}{r}-0.146 \\
0.106 \\
0.081\end{array}$ & $\begin{array}{l}-0.195 \\
-0.129 \\
-0.100\end{array}$ & $\begin{array}{l}-0.331^{* *} \\
-0.204 \\
-0.272^{* *}\end{array}$ & $\begin{array}{l}-0.176 \\
0.203^{*} \\
0.120\end{array}$ & $\begin{array}{l}-0.260^{*} \\
-0.134 \\
-0.130\end{array}$ \\
\hline $\begin{array}{l}\text { Correlation with } \\
\text { cyclical component of: }\end{array}$ & & & & & & & & & \\
\hline Investment, Std. Dev. $=0.100$ & -0.091 & -0.126 & -0.094 & -0.079 & -0.119 & -0.090 & -0.037 & -0.023 & -0.087 \\
\hline Production, Std. Dev. $=0.046$ & -0.198 & -0.069 & -0.198 & -0.172 & -0.065 & -0.199 & -0.119 & 0.064 & -0.226 \\
\hline Value Added, Std. Dev. $=0.039$ & -0.336 & -0.145 & -0.229 & -0.322 & -0.171 & -0.233 & $-0.283^{*}$ & $-0.162^{*}$ & -0.207 \\
\hline Recession & $0.024^{* * *}$ & 0.016 & 0.011 & $0.024^{* * *}$ & 0.015 & $0.012^{*}$ & $0.015^{* *}$ & 0.001 & $0.013^{* *}$ \\
\hline $\begin{array}{l}\text { Correlation with } \\
\text { cross-sectional dispersion: } \\
\text { DISPEE E } E_{t}^{\text {long }} \\
\text { DISPEE End } \\
\text { DISPEE Estort }\end{array}$ & $0.621^{* * *}$ & $0.761^{* * *}$ & $0.734^{* * *}$ & $0.618^{* * *}$ & $0.753^{* * *}$ & $0.738^{* * *}$ & $0.410^{* * *}$ & $0.540^{* * *}$ & $0.678^{* * *}$ \\
\hline Mean of raw DISPSTDEE $E_{t}^{k}$ & 0.297 & 0.251 & 0.186 & 0.295 & 0.250 & 0.186 & 0.278 & 0.236 & 0.173 \\
\hline Coeff. of Variation & 0.076 & 0.092 & 0.071 & 0.081 & 0.093 & 0.073 & 0.075 & 0.080 & 0.077 \\
\hline
\end{tabular}

Notes: See notes to Tables 19 and 20. The explanations there hold exactly here as well, replacing MEANEE $E_{t}^{k} / D I S P E E_{t}^{k}$ with DISPSTDEE $E_{t}^{k}$. The panel 'Correlation with cross-sectional dispersion' shows the pairwise correlation coefficients between DISPSTDEE $E_{t}^{k}$ and DISPEE $E_{t}^{k}$, the latter denoting the (linearly detrended and demeaned) cross-sectional standard deviations of the investment innovations. 


\section{Robustness Analysis - Firms with Longer History in the Sample}

We redo our baseline analysis from the main text body here, using only those firms from the baseline sample that had at least twenty years of observations of investment expectation errors, $E E_{i, t}^{k}$. This leaves - depending on the expectation horizon - roughly twenty percent of the original sample. Using the new sample, we compute for each year and each expectation horizon the same moments of $E E_{i, t}^{k}$ as in the main text body. The results are reported in the same way as in the main part of the paper, in the tables below.

Table 25: Summary Statistics - Pooled Cross-Section of Investment InnovaTIONS, Firms with Longer History in the Sample

\begin{tabular}{l|ccc}
\hline Statistics & $E E_{i, t}^{\text {long }}$ & $E E_{i, t}^{\text {med }}$ & $E E_{i, t}^{\text {short }}$ \\
\hline & 10,441 & 11,987 & 13,240 \\
Obs & -0.021 & -0.045 & -0.021 \\
Mean & 0.617 & 0.489 & 0.350 \\
Std.Dev. & -0.056 & -0.232 & -0.191 \\
Skewness & 4.855 & 5.398 & 6.804 \\
Kurtosis & & & \\
& & & \\
Percentiles & -1.045 & -0.884 & -0.593 \\
5th & -0.740 & -0.605 & -0.399 \\
10th & -0.345 & -0.281 & -0.174 \\
25th & -0.008 & -0.028 & 0.000 \\
50th & 0.309 & 0.209 & 0.137 \\
75th & 0.690 & 0.498 & 0.345 \\
90th & 0.979 & 0.719 & 0.516 \\
95th & & & \\
Mean of Abs $\left(E E_{i, t}^{k}\right)$ & 0.450 & 0.349 & 0.235 \\
p-values of & & & \\
Jarque-Bera Test & & & \\
Kolmogoroff-Smirnov Test & 0.00 & 0.00 & 0.00 \\
\hline
\end{tabular}

Notes: The table provides a summary of the pooled (across firm-years) distributions of $E E_{i, t}^{\text {long }}, E E_{i, t}^{\text {med }}$ and $E E_{i, t}^{\text {short }}$. The row 'Mean of $A b s\left(E E_{i, t}^{k}\right)$ ' displays the mean of the absolute values of $E E_{i, t}^{k}$. The last two rows show formal test results about the normality of the samples of investment innovations. 
Table 26: Cross-sectional Mean of Investment Innovations And the Business CyCle, Firms with Longer History in the Sample

\begin{tabular}{|c|c|c|c|}
\hline & $M E A N E E_{t}^{l o n g}$ & $M E A N E E_{i, t}^{m e d}$ & $M E A N E E_{i, t}^{\text {short }}$ \\
\hline Years & 1971-2010 & $1970-2010$ & $1970-2010$ \\
\hline Observations & 40 & 41 & 41 \\
\hline Correlation with & & & \\
\hline Investment & $0.788^{* * *}$ & $0.702^{* * *}$ & $0.473^{* * *}$ \\
\hline Production & $0.763^{* * *}$ & $0.588 * * *$ & 0.344 \\
\hline Value Added & $0.675^{* * *}$ & $0.506^{* *}$ & 0.451 \\
\hline $\begin{array}{l}\text { Correlation with } \\
\text { cyclical component of: }\end{array}$ & & & \\
\hline Investment & 0.132 & 0.177 & 0.194 \\
\hline Production & $0.457^{* *}$ & 0.330 & 0.260 \\
\hline Value Added & $0.433^{*}$ & 0.342 & $0.236^{*}$ \\
\hline Std. Dev. & 0.136 & 0.080 & 0.031 \\
\hline Recession & $-0.219^{* *}$ & -0.052 & 0.003 \\
\hline
\end{tabular}

Notes: This table provides correlation coefficients between $M E A N E E_{t}^{k}$ and cyclical aggregate activity variables for the German manufacturing sector. We use as activity variables the (linearly detrended and demeaned) growth rates, computed as differences in the natural logarithm, and the HP(100)-filtered log time series, of, respectively, West German nominal investment expenditures in manufacturing and mining, an index of manufacturing real production, and an index of manufacturing real value added. Data for the activity variables are from the German Federal Statistical Office. All time series based on expectation errors are linearly detrended and demeaned. To test for significance of the time-series correlations (in a one-sided test) we use a nonparametric overlapping block bootstrap with a four-year window and with 10,000 replications. *** denotes $1 \%$ significance, ${ }^{* *} 5 \%$ significance and $* 10 \%$ significance. The penultimate row displays the time-series standard deviation of the linearly detrended and demeaned $M E A N E E_{t}^{k}$. The last row reports a regression estimate of the $M E A N E E_{t}^{k}$ on a constant and a recession indicator. For the latter, we use the definition proposed by Bloom et al. (2012) and take the share of quarters in that year that were defined as a recession. We use the recession dates provided by the Sachverständigenrat (see Sachverständigenrat, 2009, p. 261): II/1973 - II/1975, IV/1979 - IV/1982, I/1991 - III/1993, I/2001 - II/2005 and I/2008 - II/2009. To test the statistical significance of the recession coefficient we use Newey-West standard errors to account for any potential serial correlation. 
Table 27: Cross-Sectional Dispersion of Investment Innovations and the Business Cycle, Firms with Longer History in the Sample

\begin{tabular}{|c|c|c|c|c|c|c|}
\hline & \multicolumn{3}{|c|}{ DISP = Std.Dev. } & \multicolumn{3}{|c|}{$\mathrm{DISP}=\mathrm{IQR}$} \\
\hline & $D I S P E E_{t}^{\text {long }}$ & $D I S P E E_{t}^{\text {med }}$ & $D I S P E E_{t}^{\text {short }}$ & DISPEE $E_{t}^{\text {long }}$ & $D I S P E E_{t}^{\text {med }}$ & DISPEE $E_{t}^{\text {short }}$ \\
\hline Years & 1971-2010 & 1970-2010 & 1970-2010 & 1971-2010 & 1970-2010 & 1970-2010 \\
\hline Observations & 40 & 41 & 41 & 40 & 41 & 41 \\
\hline $\begin{array}{l}\text { Correlation with } \\
\text { growth rate of: }\end{array}$ & & & & & & \\
\hline Investment, Std. Dev. $=0.092$ & $-0.512^{* * *}$ & $-0.117^{*}$ & $-0.241^{* *}$ & $-0.597 * * *$ & $-0.360^{* * *}$ & -0.167 \\
\hline Production, Std. Dev. $=0.050$ & $-0.403^{* * *}$ & 0.135 & $-0.120^{* *}$ & $-0.436^{*}$ & -0.150 & $-0.075^{* *}$ \\
\hline Value Added, Std. Dev. $=0.049$ & $-0.304^{* *}$ & 0.219 & $-0.072^{* *}$ & $-0.420^{*}$ & -0.129 & 0.010 \\
\hline $\begin{array}{l}\text { Correlation with } \\
\text { cyclical component of: }\end{array}$ & & & & & & \\
\hline Investment, Std. Dev. $=0.100$ & $-0.451^{* * *}$ & $-0.235^{*}$ & $-0.286^{*}$ & $-0.400 * * *$ & $-0.181^{*}$ & $-0.486^{* *}$ \\
\hline Production, Std. Dev. $=0.046$ & $-0.526^{* *}$ & -0.128 & $-0.220^{*}$ & $-0.526^{* *}$ & $-0.308^{*}$ & $-0.336^{* * *}$ \\
\hline Value Added, Std. Dev. $=0.039$ & -0.389 & -0.119 & -0.051 & $-0.495^{* *}$ & $-0.366^{*}$ & -0.006 \\
\hline Recession & $0.135^{* *}$ & $0.083^{* * *}$ & $0.068^{* *}$ & $0.140^{*}$ & $0.113^{* * *}$ & 0.031 \\
\hline Mean of raw DISPEE $E_{t}^{k}$ & 0.603 & 0.483 & 0.346 & 0.641 & 0.487 & 0.307 \\
\hline Coeff. of Variat. & 0.085 & 0.085 & 0.094 & 0.111 & 0.111 & 0.118 \\
\hline
\end{tabular}

Notes: See notes to Table 3. The explanations there hold exactly here as well, replacing $M E A N E E_{t}^{k}$ with $D I S P E E_{t}^{k}$. The last two rows report the mean of the time-series average of the raw DISPEE $E_{t}^{k}$, and the time-series coefficient of variation of DISPEE $E_{t}^{k}$, defined as the ratio of the time-series standard deviation of the (detrended and demeaned) series to the time-series average of the raw series. The left panel of the table operationalizes crosssectional dispersion with the standard deviation, the right panel uses the interquartile range. The numbers in the first column after the designation of the cyclical indicators display their time-series standard deviation. 
Table 28: Cross-sectional Skewness of Investment Innovations and the Business Cycle, Firms with Longer History in the Sample

\begin{tabular}{|c|c|c|c|c|c|c|}
\hline & $S K E W E E_{t}^{\text {long }}$ & $S K E W E E_{t}^{m e d}$ & $S K E W E E_{t}^{\text {short }}$ & $K E L L E E_{t}^{l o n g}$ & $K E L L E E_{t}^{\text {med }}$ & $K E L L E E_{t}^{\text {short }}$ \\
\hline $\begin{array}{l}\text { Years } \\
\text { Observations }\end{array}$ & $\begin{array}{c}1971-2010 \\
40\end{array}$ & $\begin{array}{c}1970-2010 \\
41\end{array}$ & $\begin{array}{c}1970-2010 \\
41\end{array}$ & $\begin{array}{c}1971-2010 \\
40\end{array}$ & $\begin{array}{c}1970-2010 \\
41\end{array}$ & $\begin{array}{c}1970-2010 \\
41\end{array}$ \\
\hline $\begin{array}{l}\text { Correlation with } \\
\text { growth rate of: } \\
\text { Investment } \\
\text { Production } \\
\text { Value Added }\end{array}$ & $\begin{array}{l}0.299^{* * *} \\
0.355^{* * *} \\
0.376^{* * *}\end{array}$ & $\begin{array}{r}-0.088 \\
0.049 \\
-0.014\end{array}$ & $\begin{array}{l}0.125 \\
0.073 \\
0.114\end{array}$ & $\begin{array}{l}0.279^{* * *} \\
0.416^{* * *} \\
0.439^{* * *}\end{array}$ & $\begin{array}{l}0.061^{*} \\
0.001 \\
0.099\end{array}$ & $\begin{array}{l}0.204 \\
0.192 \\
0.389\end{array}$ \\
\hline $\begin{array}{l}\text { Correlation with } \\
\text { cyclical component of: } \\
\text { Investment } \\
\text { Production } \\
\text { Value Added }\end{array}$ & $\begin{array}{l}0.146 \\
0.245^{*} \\
0.228^{* *}\end{array}$ & $\begin{array}{l}-0.160 \\
-0.233 \\
-0.129^{*}\end{array}$ & $\begin{array}{l}-0.030 \\
-0.066 \\
-0.015\end{array}$ & $\begin{array}{r}-0.097 \\
0.035 \\
0.078\end{array}$ & $\begin{array}{r}0.004 \\
-0.052 \\
0.048\end{array}$ & $\begin{array}{l}0.116 \\
0.144 \\
0.234\end{array}$ \\
\hline Recession & -0.067 & $0.338^{*}$ & 0.393 & -0.024 & 0.022 & 0.039 \\
\hline $\begin{array}{l}\text { Mean of raw } S K E W E E_{t}^{k} \\
\text { or of raw } K E L L E E_{t}^{k} \\
\text { Coeff. of Variation }\end{array}$ & $\begin{array}{l}0.059 \\
5.870\end{array}$ & $\begin{array}{r}-0.170 \\
1.756\end{array}$ & $\begin{array}{r}-0.175 \\
2.488\end{array}$ & $\begin{array}{r}-0.009 \\
9.767\end{array}$ & $\begin{array}{r}-0.032 \\
2.064\end{array}$ & $\begin{array}{r}-0.042 \\
1.811\end{array}$ \\
\hline
\end{tabular}

Notes: See notes to Tables 3 and 4. The explanations there hold exactly here as well, replacing $M E A N E E_{t}^{k} / D I S P E E_{t}^{k}$ with $S K E W E E_{t}^{k}$ or $K E L L E E_{t}^{k}$. 
Table 29: Cross-sectional Kurtosis of Investment Innovations and the BusiNESS CyCle, Firms with Longer History in the Sample

\begin{tabular}{l|ccc}
\hline & & & \\
& $K U R T E E_{t}^{\text {long }}$ & $K U R T E E_{t}^{\text {med }}$ & KURTEE $E_{t}^{\text {short }}$ \\
\hline Years & $1971-2010$ & $1970-2010$ & $1970-2010$ \\
Observations & 40 & 41 & 41 \\
& & & \\
Correlation with & & & 0.025 \\
growth rate of: & $0.264^{* *}$ & 0.261 & 0.044 \\
Investment & 0.176 & $0.289^{*}$ & 0.055 \\
Production & 0.197 & $0.266^{*}$ & \\
Value Added & & & $0.327^{* * *}$ \\
Correlation with & & & $0.246^{* *}$ \\
cyclical component of: & 0.155 & $0.150^{*}$ & 0.068 \\
Investment & $0.242^{* *}$ & $0.421^{* *}$ & \\
Production & 0.102 & 0.339 & -0.645 \\
Value Added & & & \\
Recession & -0.295 & $-1.434^{*}$ & 6.350 \\
Mean of raw KURTE $E_{t}^{k}$ & 4.676 & 5.137 & 0.130 \\
Coeff. of Variation & 0.137 & 0.161 & \\
\hline
\end{tabular}

Notes: See notes to Tables 3 and 4 . The explanations there hold exactly here as well, replacing $M E A N E E_{t}^{k}$ / DISPEE $E_{t}^{k}$ with KURTEE $E_{t}^{k}$. 
Table 30: Cross-Sectional Mean of the Individual Volatility of Investment Innovations and the Business Cycle, Firms with Longer History in the Sample

\begin{tabular}{|c|c|c|c|}
\hline & $S T D E E_{t}^{l o n g}$ & $S T D E E_{t}^{\text {med }}$ & $S T D E E_{t}^{\text {short }}$ \\
\hline Years & 1972-2009 & 1971-2009 & 1971-2009 \\
\hline Observations & 38 & 39 & 39 \\
\hline \multicolumn{4}{|l|}{$\begin{array}{l}\text { Correlation with } \\
\text { growth rate of: }\end{array}$} \\
\hline Investment, Std. Dev. $=0.092$ & $-0.566^{* * *}$ & $-0.384^{* * *}$ & $-0.177^{*}$ \\
\hline Production, Std. Dev. $=0.050$ & $-0.574^{* * *}$ & $-0.223^{* *}$ & $-0.228 * * *$ \\
\hline Value Added, Std. Dev. $=0.049$ & $-0.472^{* * *}$ & $-0.290^{*}$ & $-0.244^{*}$ \\
\hline \multicolumn{4}{|l|}{$\begin{array}{l}\text { Correlation with } \\
\text { cyclical component of: }\end{array}$} \\
\hline Investment, Std. Dev. $=0.100$ & $-0.325^{*}$ & $-0.332^{*}$ & -0.255 \\
\hline Production, Std. Dev. $=0.046$ & $-0.510^{* * *}$ & $-0.394^{* * *}$ & $-0.271^{*}$ \\
\hline Value Added, Std. Dev. = 0.039 & $-0.406^{* *}$ & $-0.340^{* *}$ & -0.010 \\
\hline Recession & $0.080^{* * *}$ & $0.049^{* * *}$ & $0.026^{* *}$ \\
\hline \multicolumn{4}{|l|}{ Correlation with } \\
\hline$D I S P E E_{t}^{\text {long }}$ & $0.537^{* * *}$ & & \\
\hline$D I S P E E_{t}^{\text {med }}$ & & $0.624^{* * *}$ & \\
\hline$D I S P E E_{t}^{\text {short }}$ & & & $0.669^{* * *}$ \\
\hline Mean of raw $S T D E E_{t}^{k}$ & 0.364 & 0.296 & 0.204 \\
\hline Coeff. of Variation & 0.081 & 0.078 & 0.069 \\
\hline
\end{tabular}

Notes: See notes to Tables 3 and 4 . The explanations there hold exactly here as well, replacing $M E A N E E_{t}^{k}$ / DISPEE $E_{t}^{k}$ with $S T D E E_{t}^{k}$. The panel 'Correlation with cross-sectional dispersion' shows the pairwise correlation coefficients between $S T D E E_{t}^{k}$ and DISPEE $E_{t}^{k}$, the latter denoting the (linearly detrended and demeaned) cross-sectional standard deviations of the investment innovations. 
Table 31: Cross-Sectional Standard Deviation of the Individual Volatility of Investment Innovations and the Business Cycle, Firms with Longer History in the Sample

\begin{tabular}{|c|c|c|c|}
\hline & $D I S P S T D E E_{t}^{\text {long }}$ & $D I S P S T D E E_{t}^{\text {med }}$ & $D I S P S T D E E_{t}^{\text {short }}$ \\
\hline Years & 1972-2009 & 1971-2009 & 1971-2009 \\
\hline Observations & 38 & 39 & 39 \\
\hline \multicolumn{4}{|l|}{$\begin{array}{l}\text { Correlation with } \\
\text { growth rate of: }\end{array}$} \\
\hline Investment, Std. Dev. $=0.092$ & $-0.472^{* * *}$ & -0.187 & -0.096 \\
\hline Production, Std. Dev. $=0.050$ & $-0.548^{* * *}$ & -0.047 & $-0.214^{* *}$ \\
\hline Value Added, Std. Dev. $=0.049$ & $-0.487^{* * *}$ & -0.099 & $-0.173^{* *}$ \\
\hline \multicolumn{4}{|l|}{ Correlation with } \\
\hline Investment, Std. Dev. $=0.100$ & -0.230 & $-0.356^{*}$ & 0.155 \\
\hline Production, Std. Dev. $=0.046$ & $-0.362^{*}$ & $-0.292^{*}$ & -0.042 \\
\hline Value Added, Std. Dev. $=0.039$ & -0.331 & -0.258 & -0.020 \\
\hline Recession & $0.068^{* * *}$ & $0.025^{*}$ & 0.016 \\
\hline \multicolumn{4}{|l|}{$\begin{array}{l}\text { Correlation with } \\
\text { cross-sectional dispersion: }\end{array}$} \\
\hline$D I S P E E_{t}^{l o n g}$ & $0.506^{* * *}$ & & \\
\hline$D I S P E E_{t}^{\text {med }}$ & & $0.539^{* * *}$ & \\
\hline$D I S P E E_{t}^{\text {short }}$ & & & $0.651^{* * *}$ \\
\hline Mean of raw DISPSTDE $E_{t}^{k}$ & 0.268 & 0.221 & 0.166 \\
\hline Coeff. of Variation & 0.102 & 0.093 & 0.088 \\
\hline
\end{tabular}

Notes: See notes to Tables 3 and 4 . The explanations there hold exactly here as well, replacing $M E A N E E_{t}^{k} /$ $D I S P E E_{t}^{k}$ with DISPSTDE $E_{t}^{k}$. The panel 'Correlation with cross-sectional dispersion' shows the pairwise correlation coefficients between DISPSTDE $E_{t}^{k}$ and DISPEE $E_{t}^{k}$, the latter denoting the (linearly detrended and demeaned) cross-sectional standard deviations of the investment innovations. 


\section{Histograms of the Investment Innovations}

Figure 3: Histograms of the Investment Innovations
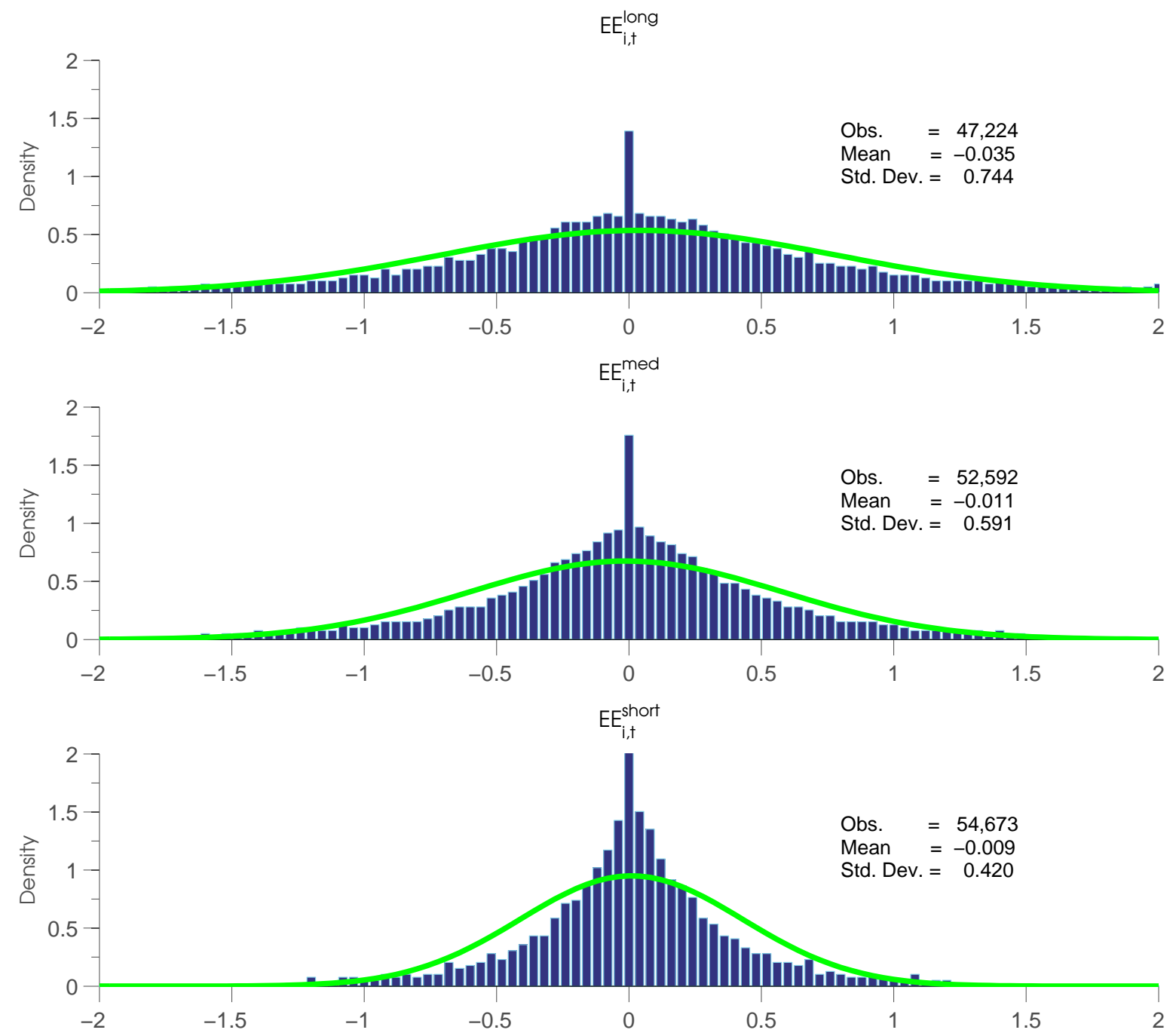

Notes: This figure shows the distributions of $E E_{i, t}^{\text {long }}$ (first panel), $E E_{i, t}^{\text {med }}$ (second panel) and $E E_{i, t}^{\text {short }}$ (third panel) for the pooled cross-section of firm-year observations of investment surprises. Each subgraph additionally shows the density function of the normal distribution (green solid line) with the same mean and standard deviation as the corresponding expectation error. 


\section{E Time Series of the Cross-sectional Moments of In- vestment Innovations}

Figure 4: Cross-sectional Mean of Investment Innovations and German Recessions
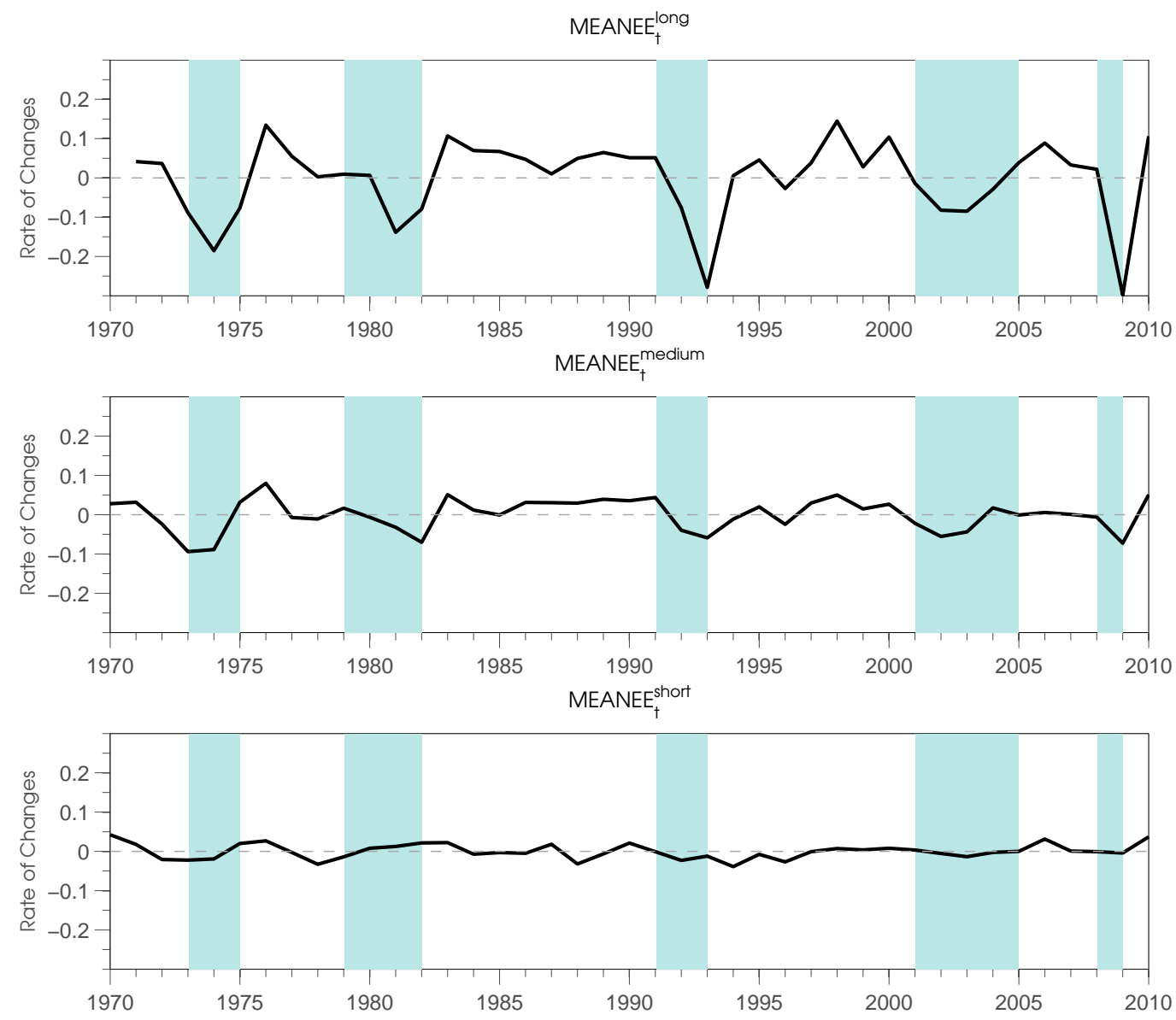

Notes: This figure shows the linearly detrended and demeaned $M E A N E E_{i, t}^{\text {long }}$ (first panel), MEANEE $E_{i, t}^{\text {med }}$ (second panel) and MEANEE short (third panel). The sample period is 1970 to 2010. Shaded regions show recessions as dated by the Sachverständigenrat (see Sachverständigenrat (2009), p. 261): II/1973 - II/1975, IV/1979 - IV/1982, I/1991 - III/1993, I/2001 - II/2005 and I/2008 - II/2009. 
Figure 5: Cross-sectional Dispersion of Investment Innovations and German Recessions
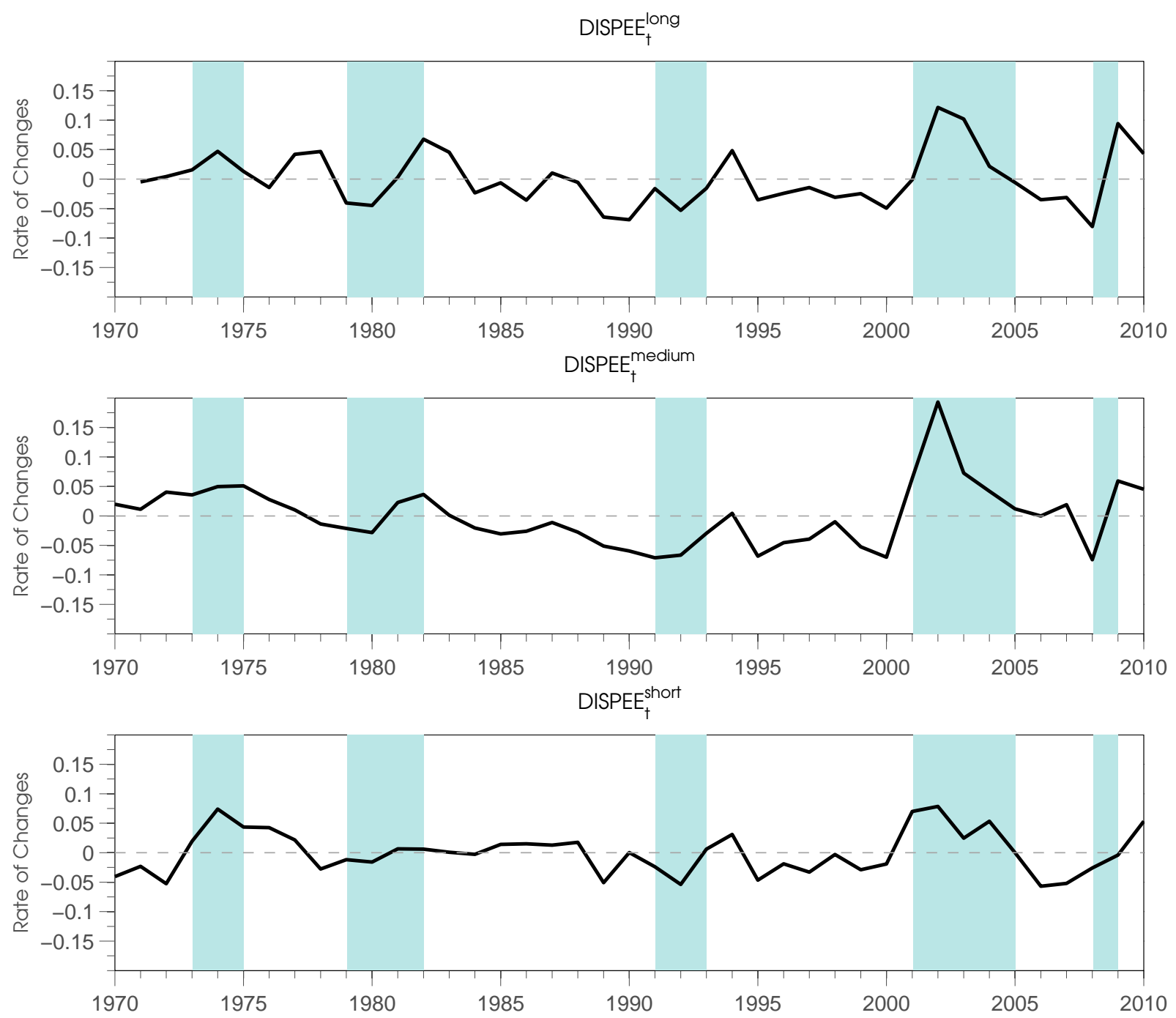

Notes: This figure shows the linearly detrended and demeaned DISPEE $E_{i, t}^{\text {long }}$ (first panel), DISPEE $E_{i, t}^{\text {med }}$ (second panel) and DISPEE $E_{i, t}^{\text {short }}$ (third panel). The sample period is 1970 to 2010. Shaded regions show recessions as dated by the Sachverständigenrat (see Sachverständigenrat (2009), p. 261): II/1973 - II/1975, IV/1979 - IV/1982, I/1991 - III/1993, I/2001 - II/2005 and I/2008 - II/2009. 
Figure 6: Cross-sectional Skewness of Investment Innovations and German Recessions
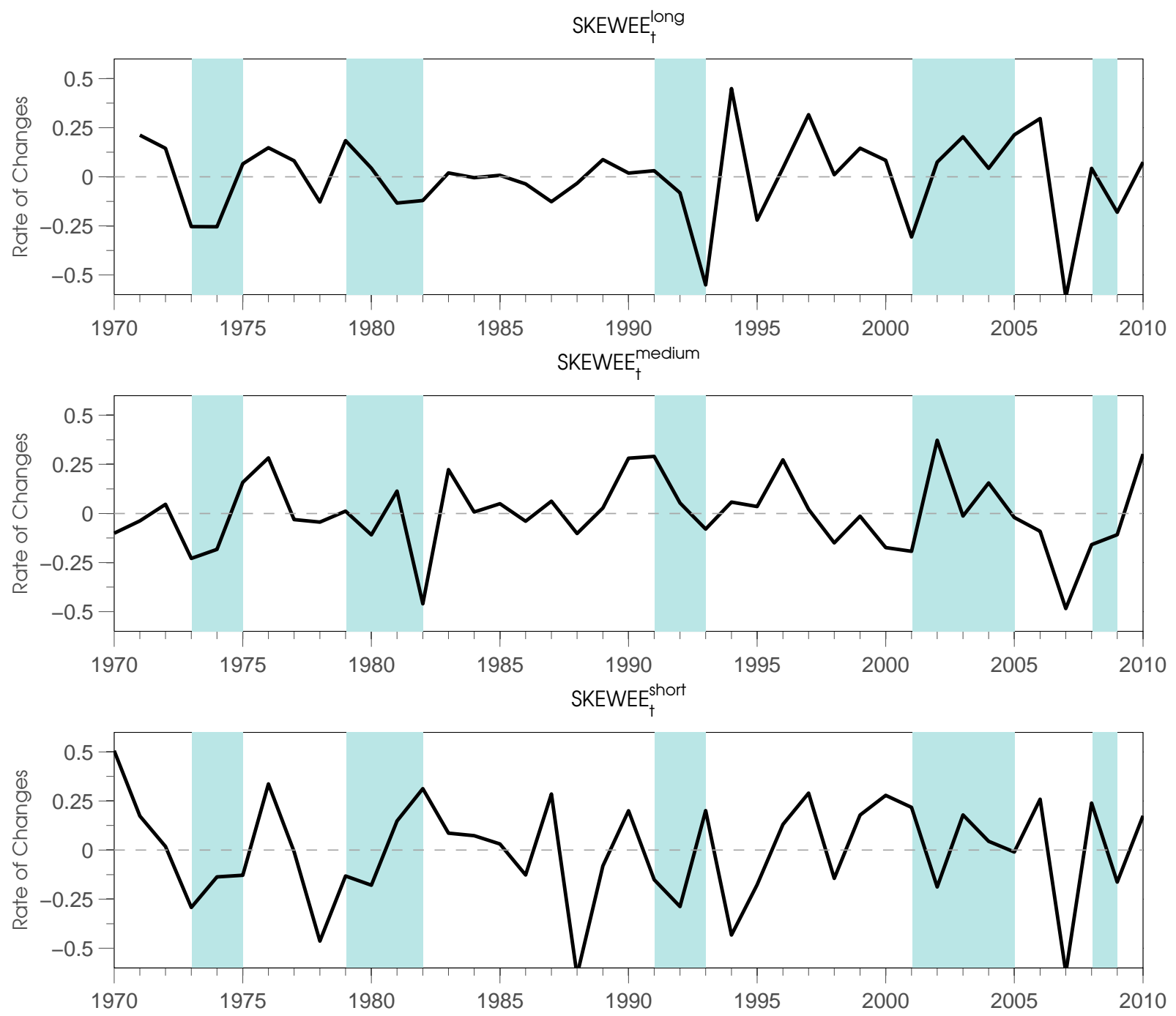

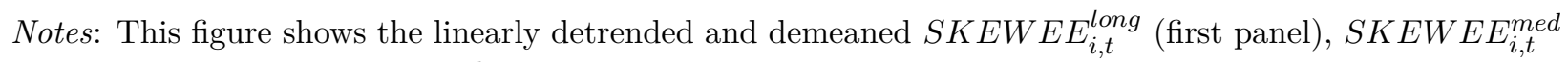
(second panel) and $S K E W E E_{i, t}^{\text {short }}$ (third panel). The sample period is 1970 to 2010. Shaded regions show recessions as dated by the Sachverständigenrat (see Sachverständigenrat (2009), p. 261): II/1973 - II/1975, IV/1979 - IV/1982, I/1991 - III/1993, I/2001 - II/2005 and I/2008 - II/2009. 
Figure 7: Cross-sectional Kurtosis of Investment Innovations and German Recessions
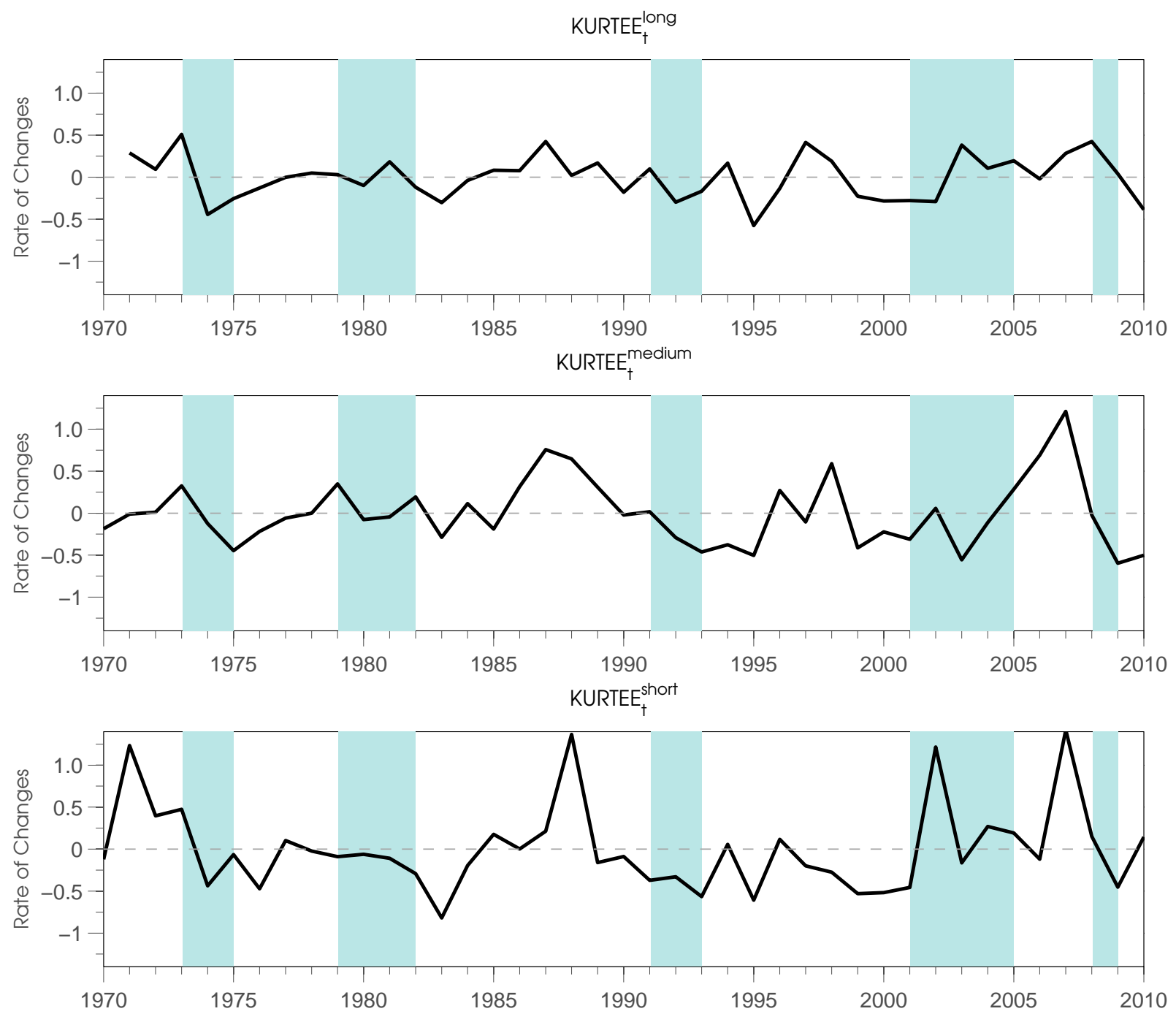

Notes: This figure shows the linearly detrended and demeaned $K U R T E E_{i, t}^{l o n g}$ (first panel), KURTE $E_{i, t}^{\text {med }}$ (second panel) and KURTEE $E_{i, t}^{\text {short }}$ (third panel). The sample period is 1970 to 2010. Shaded regions show recessions as dated by the Sachverständigenrat (see Sachverständigenrat (2009), p. 261): II/1973 - II/1975, IV/1979 - IV/1982, I/1991 - III/1993, I/2001 - II/2005 and I/2008 - II/2009. 
Figure 8: Cross-sectional Mean of the Individual Volatility of Investment Innovations and German Recessions
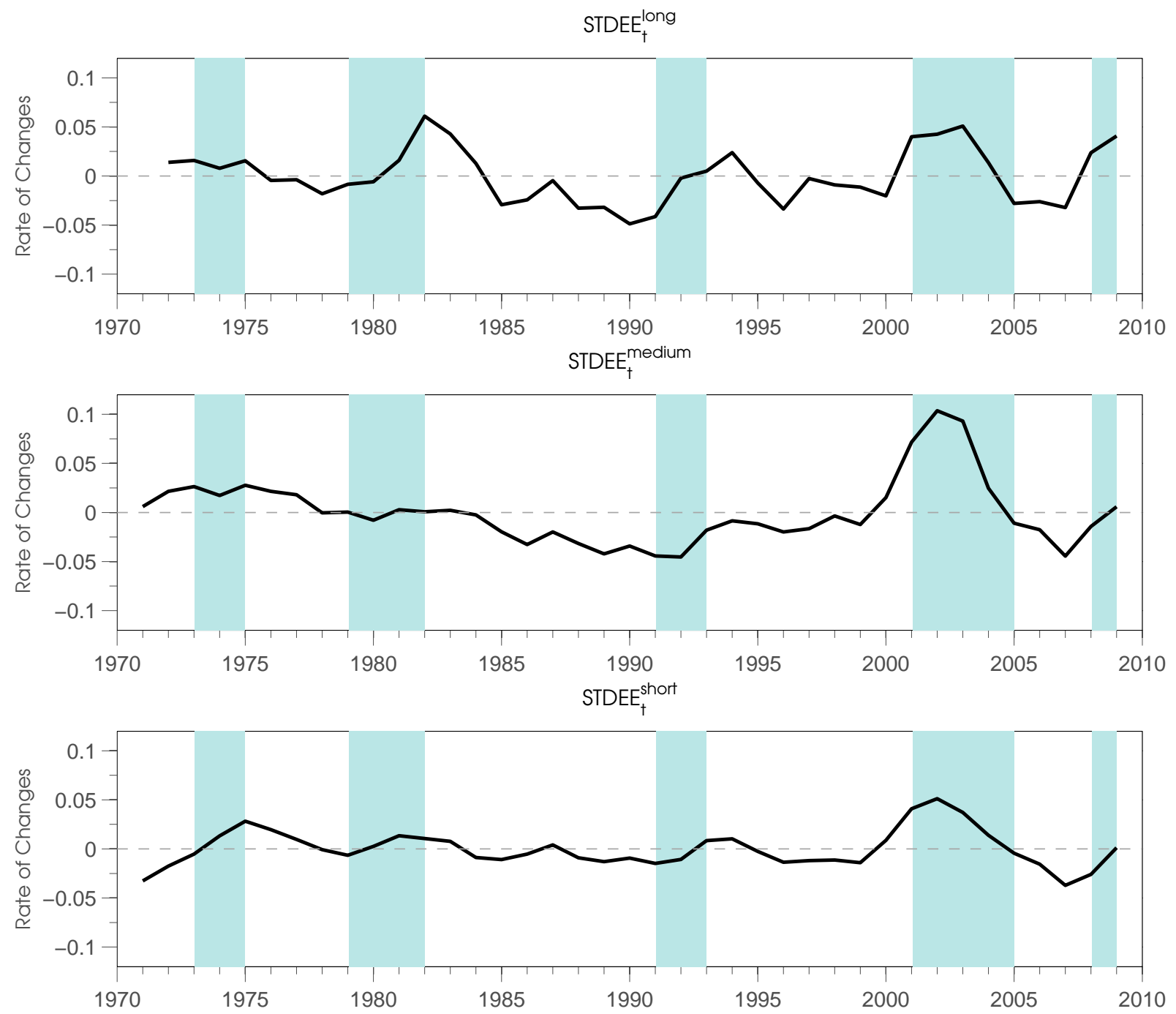

Notes: This figure shows the linearly detrended and demeaned $S T D E E_{i, t}^{\text {long }}$ (first panel), $S T D E E_{i, t}^{\text {med }}$ (second panel) and $S T D E E_{i, t}^{\text {short }}$ (third panel). The sample period is 1970 to 2010. Shaded regions show recessions as dated by the Sachverständigenrat (see Sachverständigenrat (2009), p. 261): II/1973 - II/1975, IV/1979 IV/1982, I/1991 - III/1993, I/2001 - II/2005 and I/2008 - II/2009. 
Figure 9: Cross-sectional Standard Deviation of the Individual Volatility of Investment Innovations and German Recessions
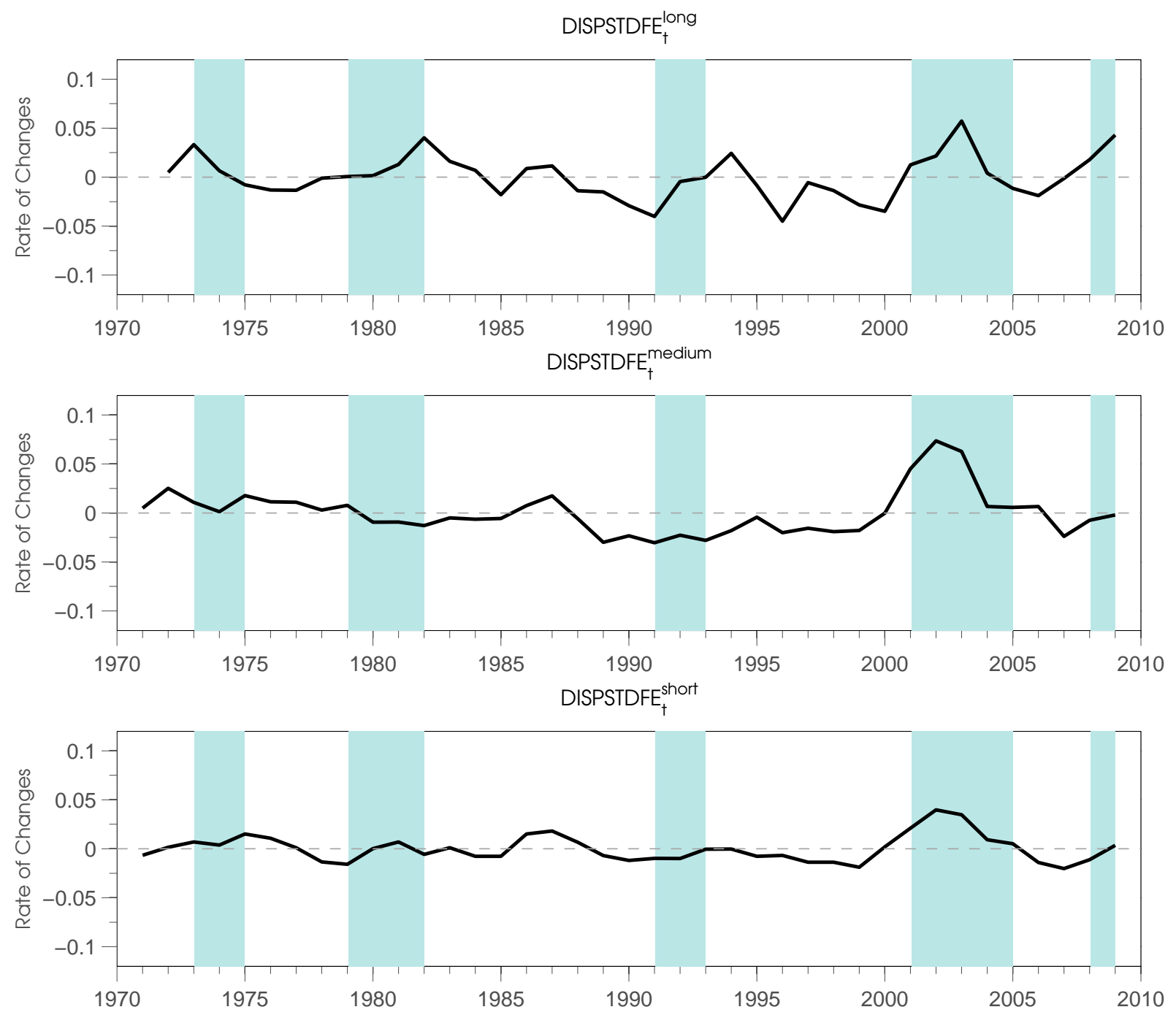

Notes: This figure shows the linearly detrended and demeaned DISPSTDEE $E_{i, t}^{\text {long }}$ (first panel), DISPSTDEE $E_{i, t}^{\text {med }}$ (second panel) and DISPSTDEE $E_{i, t}^{\text {short }}$ (third panel). The sample period is 1970 to 2010. Shaded regions show recessions as dated by the Sachverständigenrat (see Sachverständigenrat (2009), p. 261): II/1973 - II/1975, IV/1979 - IV/1982, I/1991 - III/1993, I/2001 - II/2005 and I/2008 - II/2009. 


\section{F Robustness Analysis - DISPEE, STDEE and DISPSTDEE by Industry and Firm Size}

In this appendix we show the comovement of the second moments of investment innovations, DISPEE, STDEE and DISPSTDEE, at a more disaggregated level, i.e., for the 2-digit manufacturing industries and for five employment-size quintiles.

Figure 10: Cross-sectional Dispersion, Mean of the Individual Volatility and Standard Deviation of the Individual Volatility of Investment Innovations By 2-Digit Industry

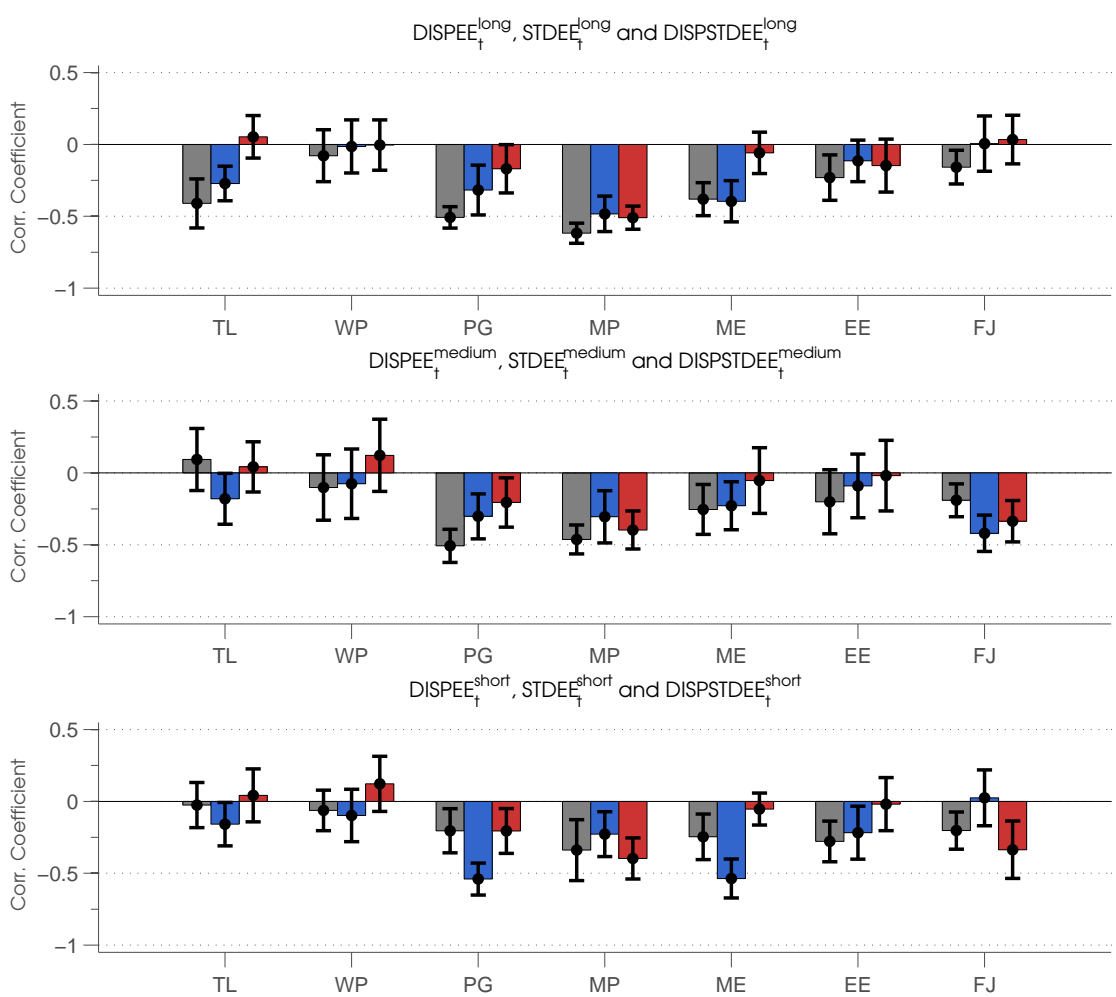

Notes: This figure shows the correlation coefficients of the linearly detrended and demeaned industry-specific moments of the investment innovations-DISPEE $E_{i, t}$ (grey bar), STDE $E_{i, t}$ (blue bar), and DISPSTDE $E_{i, t}$ (red bar) - with the growth rate of nominal investment in the same industry for the long-horizon investment innovations (first panel), for the medium-horizon innovations (second panel), and for the short-horizon innovations (third panel). The acronyms \{'TL','WP','PG','MP','ME','EE','FJ'\} stand for TL: Textile and Leather Products; WP: Wood, Paper and Printing; PG: Plastic, Ruber, Glass and Ceramics; MP: Metal Products; ME: Machinery and Equipment; EE: Electrical Equipment; FJ: Furniture and Jewelry. The error bars (black line) are the $95 \%$ confidence intervals for these correlation coefficients. 
Figure 11: Cross-sectional Dispersion, Mean of the Individual Volatility and Standard Deviation of the Individual Volatility of Investment Innovations By Firm-Size Quintile
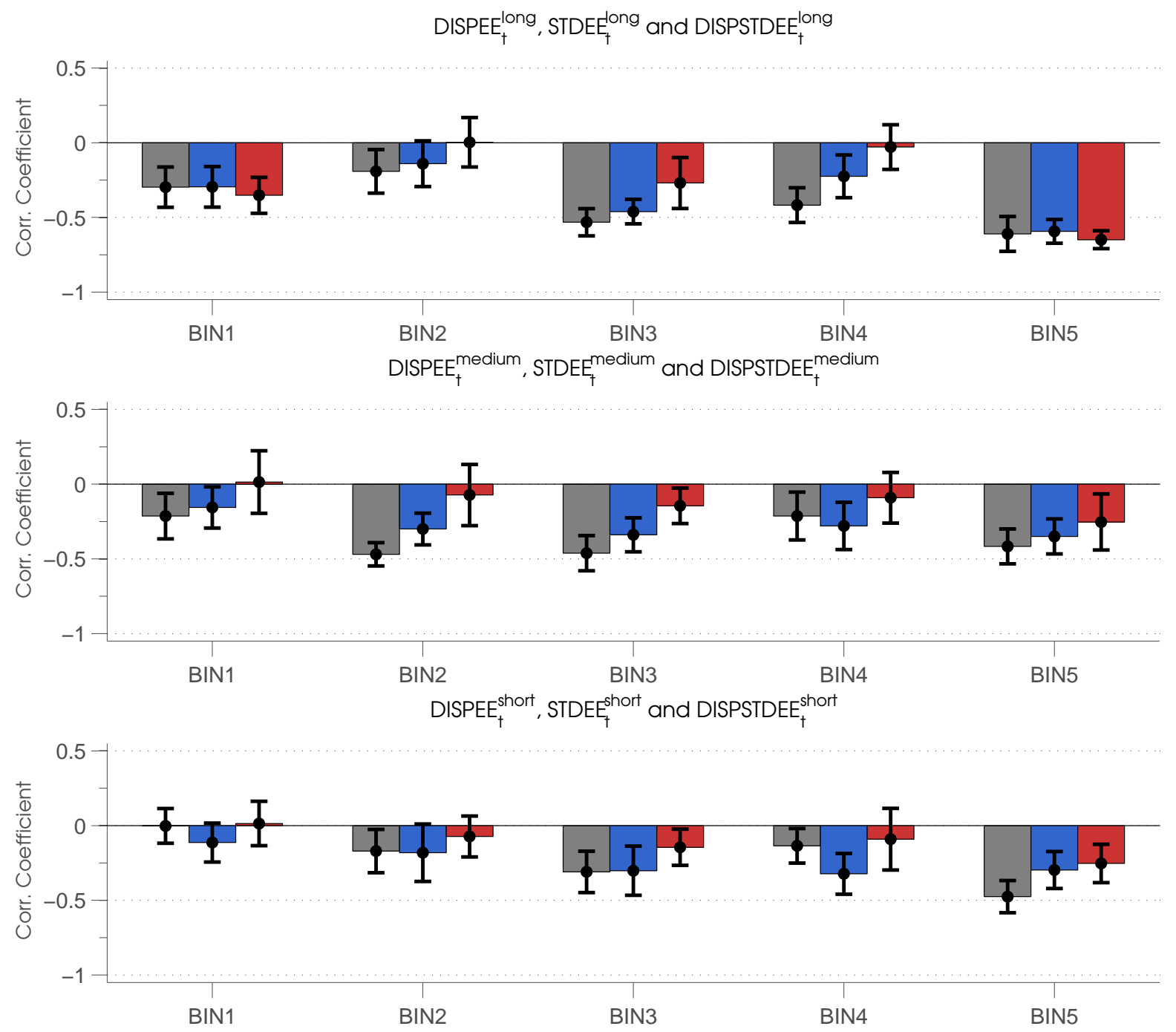

Notes: This figure shows the correlation coefficients of the linearly detrended and demeaned firm-size-specific moments of the investment innovations-DISPEE $E_{i, t}$ (grey bar), STDE $E_{i, t}$ (blue bar), and DISPSTDE $E_{i, t}$ (red bar) - with the growth rate of total manufacturing nominal investment for the long-horizon investment innovations (first panel), for the medium-horizon innovations (second panel), and for the short-horizon innovations (third panel). $\{\mathrm{BIN} 1, \mathrm{BIN} 2, \mathrm{BIN} 3, \mathrm{BIN} 4$, and BIN5 $\}$ stands respectively for firms which employed on average (i) less than 52 workers (first quintile); (ii) between 52 and 135 workers (second quintile); (iii) between 135 and 305 workers (third quintile); (iv) between 305 and 796 workers (fourth quintile); and, (v) more than 796 workers (fifth quintile). The error bars (black line) are the $95 \%$ confidence intervals for these correlation coefficients. 


\section{G Robustness Analysis - Five-year Rolling Window Standard Deviation of the Firm's Investment Inno- vations}

In this appendix, we revisit the results from Section 5 of the main text on firm-individual volatility replacing the three-year rolling window standard deviation of the firm's investment surprises with a five-year one.

Table 32: Cross-sectional Mean of the Individual Volatility of Investment Innovations and the Business Cycle, Five-year Windows

\begin{tabular}{|c|c|c|c|}
\hline & $S T D E E_{t}^{l o n g}$ & $S T D E E_{t}^{\text {med }}$ & $S T D E E_{t}^{\text {short }}$ \\
\hline Years & 1973-2008 & 1972-2008 & $1972-2008$ \\
\hline Observations & 36 & 37 & 37 \\
\hline \multicolumn{4}{|l|}{$\begin{array}{l}\text { Correlation with } \\
\text { growth rate of: }\end{array}$} \\
\hline Investment, Std. Dev. $=0.092$ & $-0.231^{* *}$ & -0.215 & $-0.271^{* *}$ \\
\hline Production, Std. Dev. $=0.050$ & -0.205 & -0.059 & $-0.341 * * *$ \\
\hline Value Added, Std. Dev. $=0.049$ & $-0.300^{*}$ & -0.079 & $-0.319^{* *}$ \\
\hline \multicolumn{4}{|l|}{$\begin{array}{l}\text { Correlation with } \\
\text { cyclical component of: }\end{array}$} \\
\hline Investment, Std. Dev. $=0.100$ & -0.190 & -0.254 & -0.251 \\
\hline Production, Std. Dev. $=0.046$ & $-0.376^{* *}$ & -0.285 & $-0.470^{*}$ \\
\hline Value Added, Std. Dev. $=0.039$ & $-0.363^{* *}$ & $-0.339^{*}$ & -0.296 \\
\hline Recession & $0.021^{* * *}$ & 0.025 & $0.013^{* *}$ \\
\hline \multicolumn{4}{|l|}{ Correlation with } \\
\hline cross-sectional dispersion: & & & \\
\hline $\begin{array}{l}D I S P E E_{t}^{\text {long }} \\
D I S P E E_{\text {med }}^{\text {med }}\end{array}$ & 0.288 & O $686 * * *$ & \\
\hline DISPEE $E_{t}^{\text {short }}$ & & 0.000 & $0.616^{* * *}$ \\
\hline Mean of raw $S T D E E_{t}^{k}$ & 0.446 & 0.362 & 0.248 \\
\hline Coeff. of Variation & 0.059 & 0.089 & 0.065 \\
\hline
\end{tabular}

Notes: See notes to Table 7 in the main text. The explanations there hold exactly here as well, except that the window for the firm-individual standard deviation of investment surprises has been increased to five observations of $E E_{i, t}^{k}$. 
Table 33: Cross-Sectional Standard Deviation of the Individual Volatility of Investment Innovations and the Business Cycle, Five-year Windows

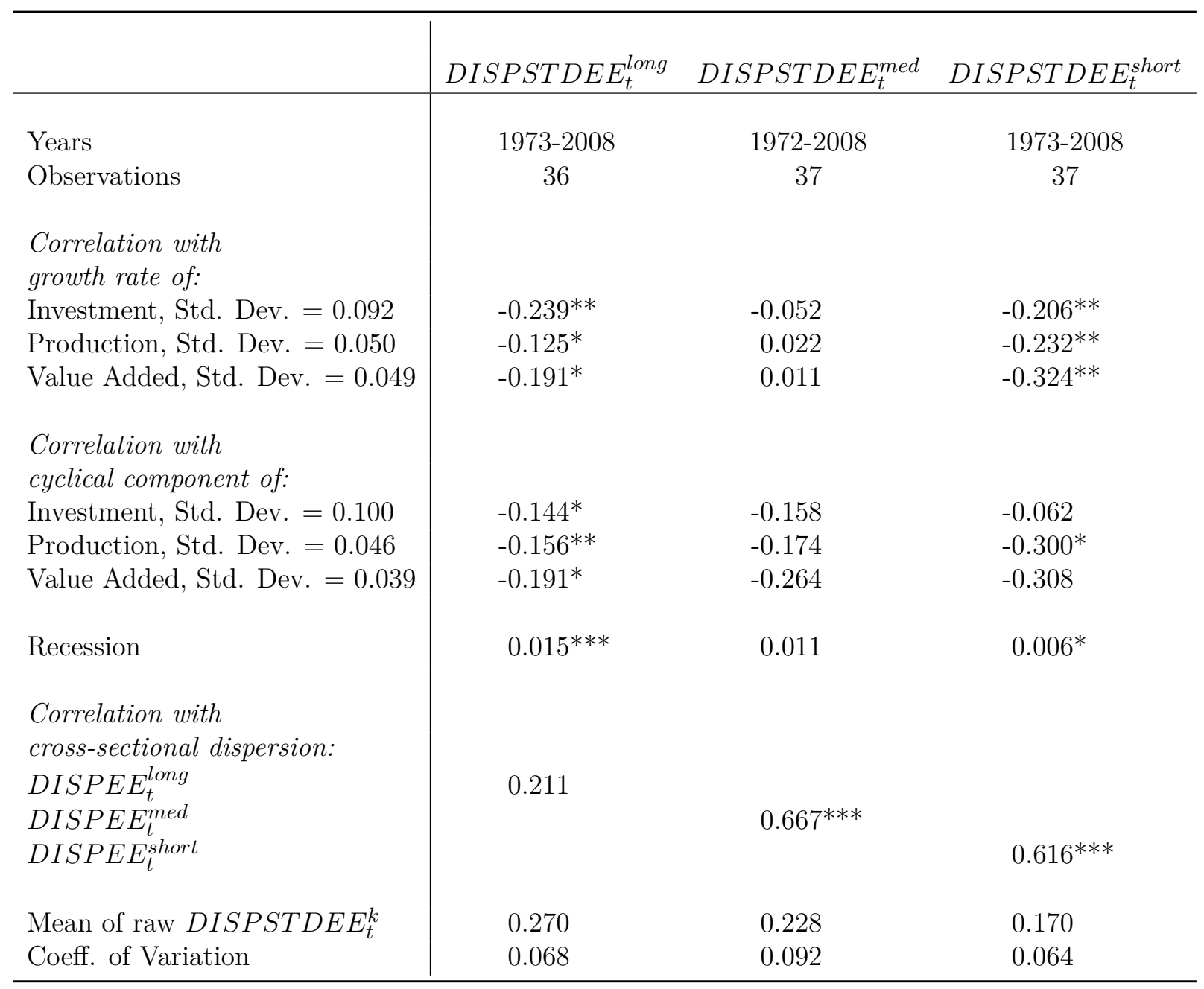

Notes: See notes to Table 8 in the main text. The explanations there hold exactly here as well, except that the window for the firm-individual standard deviation of investment surprises has been increased to five observations of $E E_{i, t}^{k}$. 